secteurs ou aujourd'hui la surface du platean se termine en falaise et est completement nue. ils sont très réduits ou mème tolalement absents lia ou le rempart est encore relativement bien conservé : il est significatif par exemple qu'au-dessus du point il la masse des pierres entassées à mi-pente cesse brusquement au droit du début de la muraille. Il est donc vraisemblable de considérer ces grandes trainées de pierres comme des décombres provenant soit de murs qui. a l'origine, couronnaient peut-ìtre le plateau sur tout son périmetre, soil de ruines d'habitations en pierres seches, comme l'indique la présence de fragments de meules plates. Elant donné que ces tas de pierres ne sont pas situés immédiatement au-dessous du pied de la falaise. mais a quelque distance sur la pente. on peut se demander si ces construclions - remparls ou maisons. - n'ont pas été rasées jusqu'au roc et projetées violemment vers le bas : un démantèlement radical était facilement réalisable partout ou les murs reposaient sur les strates horizontales de la surface supérieure du promontoire.

L'absence totale de vestiges postérieurs is l'an 50 av. J.-C. ainsi que l'anéantissement complet de la struclure des habilations, qui n'ont jamais été relevées par la suile, pourrail indiquer que le caslellum gabale du Roc de la Fare a été détruil au cours d'une action militairets précédant immédialement la romanisation du pass. peut-itre au cours de la Guerre des Gaules.

\section{André sourou}

P.-S. - In fragment de ceramique gauloise ¿ décor oculé. actuellement déposé au Musée de Mende (Lozère), provient des environs de Montredon (cf. P. Brocilist et A. Soltor, Céramiques et monnaies gauloises de Lozère, Ogam. 1959, p. $396 \mathrm{sq}$.) : peut-être a-t-il été trouvé sur le Roc de la Fare ? Sa présence en cet endroit ou dans quelque tombe correspondant a l'habitat semble, en tout cas, tout a fait normale. -... Nous avons pu constater également que la céramique ornée du for de la Fare est identique à celle que l'on peut recueillir à l'intérieur de l'enceinte de Garastre commune de Saint-Vincent-de-Barbeyrargues. II (imalt) ${ }^{47}$.

\section{S.}

(16) Les grands blocs de calcaire brut placés sur le bord de la falaise, que nous avons mentiomnes au début de cette étude, semblent avoir été disposés en ces endroits pour être projetés sur les assaillants.

(17) R. et I. Allégre, Le cap-barré de Garastre, Cahiers d'Histoire et d'Archéologie, Nîmes, $15^{\mathrm{e}}$ cahier, 1937 , p. 491-501 et plus particuliorement planche 1 , p. 196.

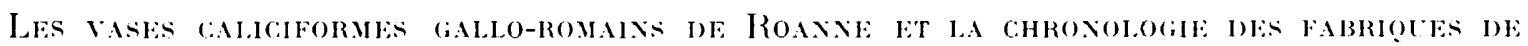

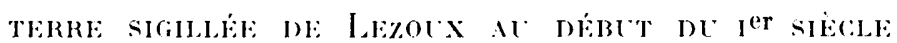

\section{Les rases 11 de Roanne}

Les vases caliciformes à panse décorée. forme 11 dans la rlassification de Dragendortl. ne sont pas très fréquents dans les fouilles archéologiques de France. On en trouve quelques-uns, fabriqués en Italie où cette forme connut une grande vogue. Ils ont été importés d'Arezzo, surlout a l'époque d'Auguste. Bien que rares. ceux qui ont élé moulés dans des aleliers gaulois sont particulierement importanls pour l'étude de l'évolulion de la terre sigillée gallo-romaine. Ils sont. en effel. le plus souvent les lémoins d'une influence directe des productions italiques sur les fabriques gauloises. qui devaient présenter par ailleurs tress tot un style régional dans leur décor comme dans leurs formes.

Pour celle raison. nous voudrions reprendre et compléter. par des documents ef des observations nouvelles. l'étude magistrale mais qui porte sa date. que Joseph Jéchelelle arail consacrée aux vases Dragendorfl 11. découverts a Roanne' ${ }^{1}$. Acluellement. cel ensemble nous parait le plus important qui

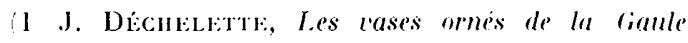
romaine, 1, p. 23-25, 6r-69. 


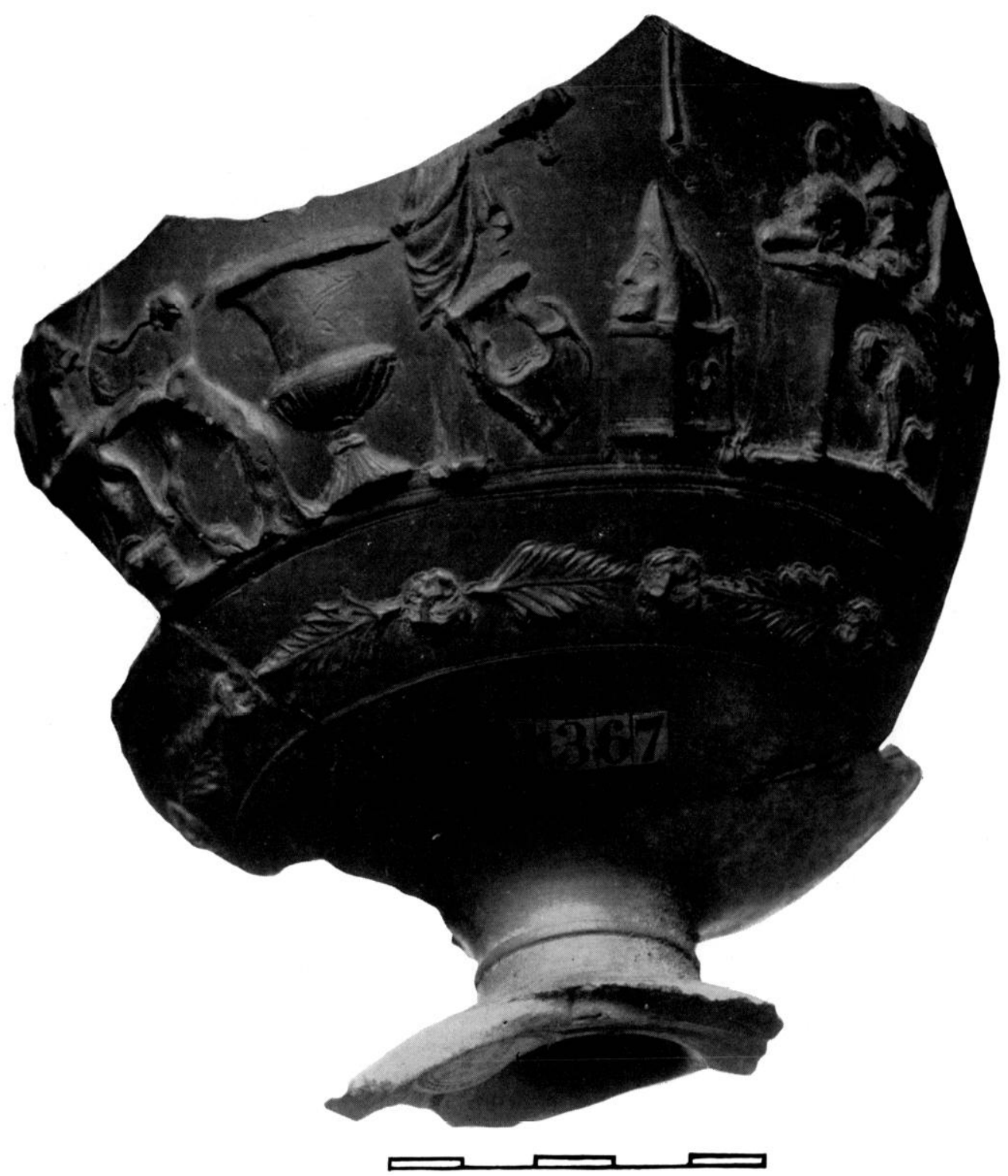

Fïg. 1. - Vase arétin, $n^{0} 1$, série $A$ de la main du potier Rasinius.

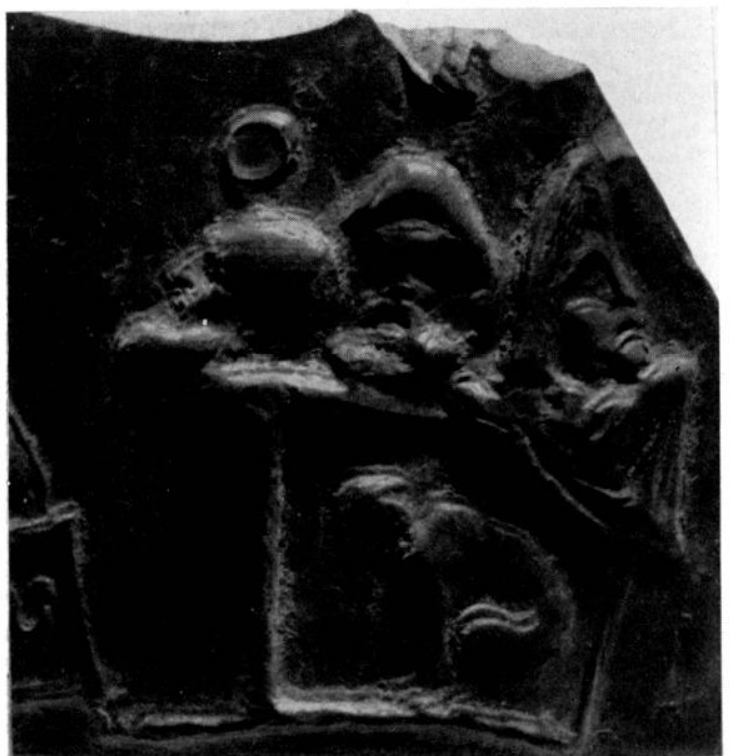

Figr. 2. - Détail du vase $n^{\circ} 1$, série $A$, montrant la table chargée de trois masques scéniques. On voit la panthere assise dessous et le sommet du liluus.

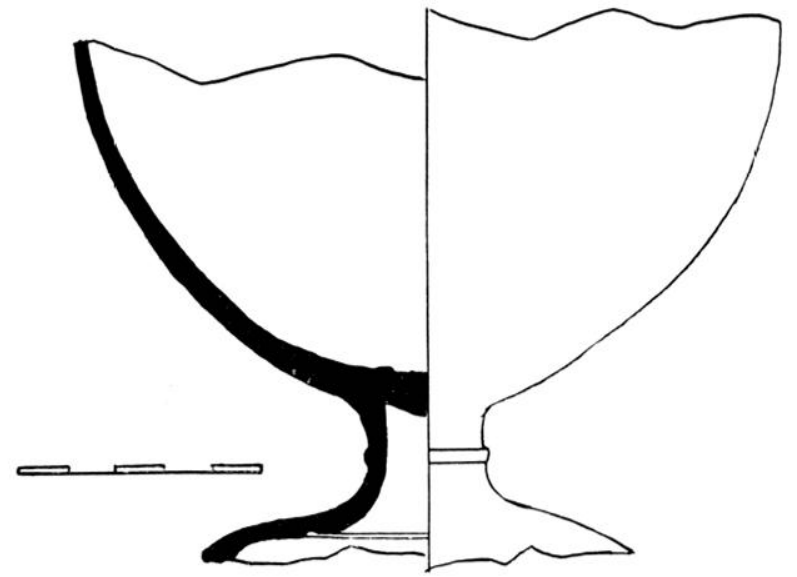

Fin. 3. - Profil du rase $\|^{\circ} 1$, sírie A. 
existe en France, par le nombre, la variété. la beauté et l'importance. Aussi avons-nous demandé au professeur Arturo Stenico, spécialiste des vases d'Arezzo, de nous donner son avis sur la date et l'attribution des documents arétins, ce qu'il a fail avec une très grande amabilité, et à M. Robert Périchon, chargé de classer la Bibliothèque Joseph Déchelette de Roanne, de nous rechercher l'origine des vases et de dessiner leur profils. Il a tout fait, en plus, pour nous faciliter le travail sur place, et je ne saurais jamais assez remercier ces deux savants de leur précieuse collaboration.

Plusieurs de ces documents ont été trouvés dans les nécropoles gallo-romaines de Roanne; mais le contenu de chaque tombe n'a pu être isolé el étudié séparément ${ }^{2}$. Les conditions de la recherche ne le permettaient pas. Les autres ont été découverts en divers points de la ville, mais il n'est pas possible non plus, malgré les recherches de M. Périchon, de connaître dans quel contexte. Nous sommes réduits a faire une étude des vases en euxmêmes. Nous savons seulement, d'après les conclusions de Déchelette, confirmées par les fouilles récentes du groupe archéologique de Roanne, que l'époque la plus active du passé de la ville se place sous le règne d'Auguste et, probablement, sous celui de ses successeurs immédiats ${ }^{3}$. C'est vraisemblablement pendant ce temps-là que la ville importe ces produits céramiques. Mais l'indication n'est pas très précise. L'ensemble comporte, suivant notre classement, qui diffère de celui de J. Décheletle, trois séries :

A. Vases importés d'Arezzo. - No 1 (fig. 1. 2 et 3 ). Trouvé le 22 mars 1902 , dans les fondations du petit Collège, quartier de la Livatte, Roanne. Musée de Roanne, no 1367. -Bibliographie: J. Déchelette, Vases ornés de la Gaule romaine, I, p. 22-23, fig. oे. Arturo STEvico, Revisione critica delle Pubblicazioni sulla ceramica arrelina, 1960, no 139, p. 23.

(2) DÉcheletTi, I.a nécropole gallo-romaine de Rranne, dans Bullelin de la Itana, XIII, 1904, p. 10 du tiré à part.

(3) Díchelette, ibidem, p. 40.
Terre rouge tris fine, vernis rouge. un peu orangé, proche de $\mathrm{F} 16^{3 \mathrm{bis}}$. Dimensions, hauteur du tesson : $11 \mathrm{~cm} .8$; diam. : $14 \mathrm{~cm}$. 4. Partie inférieure d'une belle coupe. La décoration se compose d'attributs dionysiaques. On y voit deux tables chargées d'offrandes: l'une, de forme ronde (delphica), soutenue par des pieds d'animaux, porte une nébride, un masque tragique (Dionysos?), vu de face, un canthare, un tympanum et une double flûte (?). Une panthère, debout, appuie ses pattes de devant sur le rebord de cette table. On distingue au-dessous une ciste, ou plutòt un calathos. L'autre table, de forme rectangulaire, a pour supports de simples pieds droits : elle est recouverte en partie d'une draperie chargée de trois masques scéniques et d'un liluxs; au-dessous, une panthère se tient accroupie, (fig. 2). Entre les deux tables, on voit un large cratère décoré d'une guirlande de lierre, un hermès drapé dont le buste manque et au pied duquel repose une cithare, enfin une ciste rectangulaire avec une anse visible, et vraisemblablement une autre derrière, dont le couvercle est surmonté d'un grand masque scénique. Les emblèmes dionysiaques de cette coupe offrent une grande similitude avec ceux qui décorent la célèbre coupe en sardonyx. dite des Ptolémées, conservée au Cabinet des Médailles ${ }^{4}$ et dont Ie style scmble inspiré d'un travail de toreutique. Une delphica chargée de vaisselle orne aussi un des magnifiques shyphoi du trésor de Boscoreale ${ }^{5}$.

Le professeur stenico attribue ce vase au potier Rasinius ${ }^{6}$, qui a travaillé sous le règne d'Auguste. Les productions de cet artisan ont été vendues abondamment loin de son lieu de travail, Arezzo; on a retrouvé bon nombre

(3 bis) Les couleurs sont donnes d'apris le Code expolaire de A. Cantilic et G. TAYLor.

(4) E. Babelox, Calalogue des camees de la Bibliothèque nationale, pl. XI.lI , fig. 368 et p. 201.

(5) A. Hérox ne: Vir.tirossf, Le lrésor de Boscoreale. dans Monumenls Piol, V, pp. 79 et 208, fig. 5l, pl. XV, n०2.

(6) Autres fragments de la mème matrice : Stexico, Ceramica arretine a relievo della coll. Pisani-Lossi del Museo di Milano, dans Sludi in onore di Arislide Calderini e Roberto Paribeni, III, 1956, no 62 a, e, b. Sur Rasinius, cf. Stwico, La ceramica arretina, $I$, Rasinius I, Milan, 1960. 


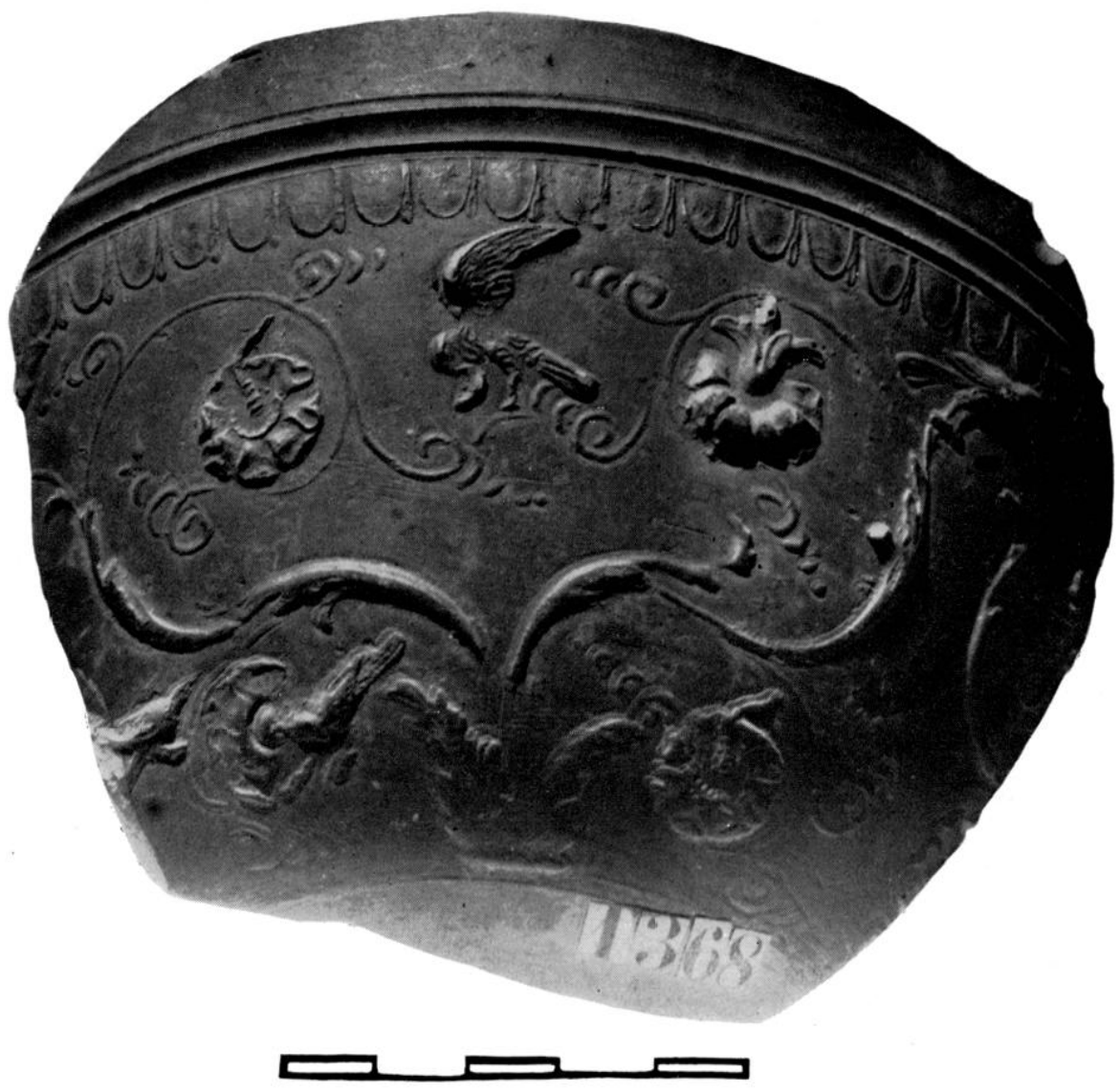

l:ï. 1. Fragment de la panse d'un vase aritin $n^{\circ} \cdot$. sirie $A$.

de ses vases en Espagne. en Giaule. au Sord des Apes. Ians le centre de la ciaule. a quatre-vinet kilometres de lioanne a rol d'oiseau. on peut signaler à lierorovie des vaisselles lisses estampillées de son nom et les fragmenls d'un beau cratère signé d'un de ses esclaves : Certus Rasinit. On y roit entre autres un personnage de profil enveloppé d'amples vètements flotlants qui. de ses deux poings, s'appuie, vers la gauche. sur une lable a Lrois pieds.

Ce fragment dale de la de moilie du regune d'Augrusle (-10 av. 10 après J. C.:.

$N^{\circ} 2$ (lig. 4). Mème provenance que le no l. Musee de Roamne. no 1:368. Bibliographie:

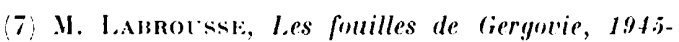
19.46, dans Gallia, VI, 19.18, 1, p. $70-71$ et fig. 17 : cratère de Rasinius. J. Wand-Prakiss, The Pollery of Gergovia, p. 78 : estampilles "Rasini "et "Acastus ", esclave de Rasinius.

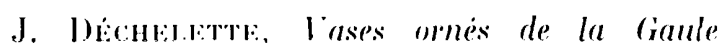
romaine. I. p. 2:3. fig. (i; Felix (Oswald) el

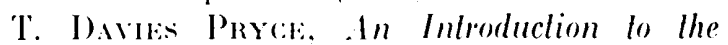
Study of Terra sigillata. pl. XXV. p. 1333 at autres.

Terre rouge, vernis rouge. entre F 16 el F 18. Dimensions du lesson, 9 cm. 2 sur $11 \mathrm{~cm} .8$. Fragmenl de panse. En haul, courl une ligne d'oves a pendentifs un peu renfles. lu-dessous, de larges rinceaux at volutes sortent d'une rorbeille de feuilles el se lerminent par des vrilles de vigne. Ils portent. des fleurs de trois espores diflérentes. vues. non de face. mais de Irois-quarls. Au centre du decor, un oiseau. les ailes relevés. contourne son cou vers le bas. comme s'il regardait un objet par dessous. In autre. un peu plus haut que lui. perche au sommel d'une feuille, est tourne vers la droite. In troisieme en bas. a gauche, picore le corur d'une lleur.

Nous avons la un bel exemple d'art augus- 
teren. que nous pouvons comparer par exemple aux bas-reliefs de l'dea Pacis ef a l'aroenlerie de l'épocpue. On y voil précisement de riches rinceaux nassant a la base de deux toufles de feuilles. comme ied et s'elalanl sur toule la surface a décorer. A parlir du commencement de l'Empire -... el pour longlemps encore -. le motif est en grande faveur dans la sculpture décorative en marbre. sur les frisess architerconiques. sur les vases, sur les e puleali ". less randélabres... Ia toulfe est plus ou moins fournie. Ainsi se gonfle-telle sur l'Ara Pacis ${ }^{8}$. le bige en marbre du llusée du Valican". le manche de la lrulla de Chatuzanges (I)romeso. le gobelet d'areent d'Alexandrie" lei, elle est plus simple mais le principe est le meme. les fleurs, Iris solgnées. Irese variés, ne sont pas dillérentes de celles de l'. Ira Pacis ou des deux coupes du lrésor de Boscoreale ${ }^{22}$ sur ces vases d'arogent. c'est la meme disposition : sur laxe des toufles et entre les volules des branches qui montent de celles-ci. un élément animal anime le décor végélal. Ajoutons encore ceci : le grand oiseau central a la mème allilude que le cyone de Iéda ${ }^{13}$. en relief sur un miroir de mélal, de Boscoreale alssis, ou qu'un autre, sculpté sur la frise inférieure externe de l'Ara Pacis.

On sail combien les rases arétins doivent aux mures mélalliques contemporaines. "La céramique à relief fournil aux archéologues. comme aux paurres d'autrefois, le meilleur succédané de l'orfèvrerie précieuse "14. Récemment encore. on a comparé de fagon tres

(8) Par ex. : li. Stroxia, la scullura romana da luguslo a Conslanlino, p. 43 , fig. 23.

(9) E. Stroxi, op. cil., pl. Nil.

(10) Wartins, Calal. of the silver Plale, Cir., Elr. and Rom. in the Br. Wus., 1921, pl. XIX, 135.

(11) A. Anнгах, I.e gobelel en argent des amours vendangeurs du Musee d'Alexandrie, Societé royale d'archeologie d'Alexandrie, cahier $n^{\circ} 1,1939$.

(12) HÉRON DE Villefosse, Le lrésor de Boscoreale, dans Monumenls Piol, V, 1899, pl. IX et X.

(13) Ilf́rox de Villefosse, op. cil., pl. 20.

(14) F. Wullecmer, Le Trésor de Tarenle, p. 81.

(15) M. Labroc'ssr:, Gallia, XII, 1954, p. $301 \mathrm{sq}$. (h. Picari), D'un lesson arélin trouvé à Sainl-Berlrandde-Comminges à l'un des shyphoi d'argent du lresor de IIoby (Copenhague). dans Hommages a Haldemar Deonna, coll. Iatomus, XXVIII, p. 373-38.1, pl. I.III. I II. précise un lesson troure a saint-Berl rand-de-

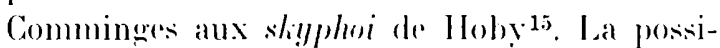
bilite de reporter directement des reljels du mét al sur l'argile par surmoulace a ele emplové de lous lemps par les ceramisles, qui ont fail ce travail de facon plus ou moins habile. Ce n'est pas le ras icio ou le decor est d'un seul lenant. pour ainsi dire. Fin effet il est impossible techniquement de mouler directement la décoration enliere des vases de celle forme hémisphérique aver de l'arqule, car la lerre. en se desséphant, enserrerail si edroilement l'original qu'on ne pourrail démouler. Nous sommes done amenés a conclure que l'auleur du moule de celle coupe chail un arlisle aussi habile que les orliveses qui concevaient des ensembles analogues, el non point un aslucieux manicur de poincons-matrices.

Le style du rase de Roanne rappelle celui du potier M. Perennius Tigramus ${ }^{16}$ el d'autres potiers "pré-ligraneens". de Cin. Mleius ou Rasinius. Le professeur stenico penche pour Rasinius, mais soumet son allribulion i plusieurs réserves, notamment à cause de la présence des oiseaux.

Ce tesson date de la 2 e moitié du règne d'Auguste (-10 avant +10 après .J. C.).

B. Vase de la Graufesenque. No 1 (fig. :) et 6). Trouvé dans la nécropole de Roanne.

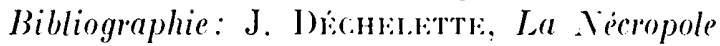
gallo-romaine de Roanne. 1904. p. 24. fign. I1 ; Vases ornés de la Gaule romaine, I, p. 68 el pl. 1. Felix Osward el T. I)avils Pryce: op. cil., pl. XIX.

Couleur rouge assez sombre. entre H 16 el F 18. Ia couleur de la pâle est peu visible.

Dimensions: haut. 15) ( $\mathrm{m} .2$; diametre 22 centimetres.

Ce vase est un des plus beaux, si ce n'est le plus beau vase 11 des oflicines de la Ciraufesenque que l'on ait publié en France, tant par son décor que par sa conservation. Le pied seul est en grande parlie disparu mais il en demeure assez pour que l'on en connaisse le profil exact.

Le décor est divisé horizontalement el verti-

16) DnaginorF-Warmail:n, Arrelinische Reliefkeramik, 19.48, pl. 12, nos $18.1-185$. 


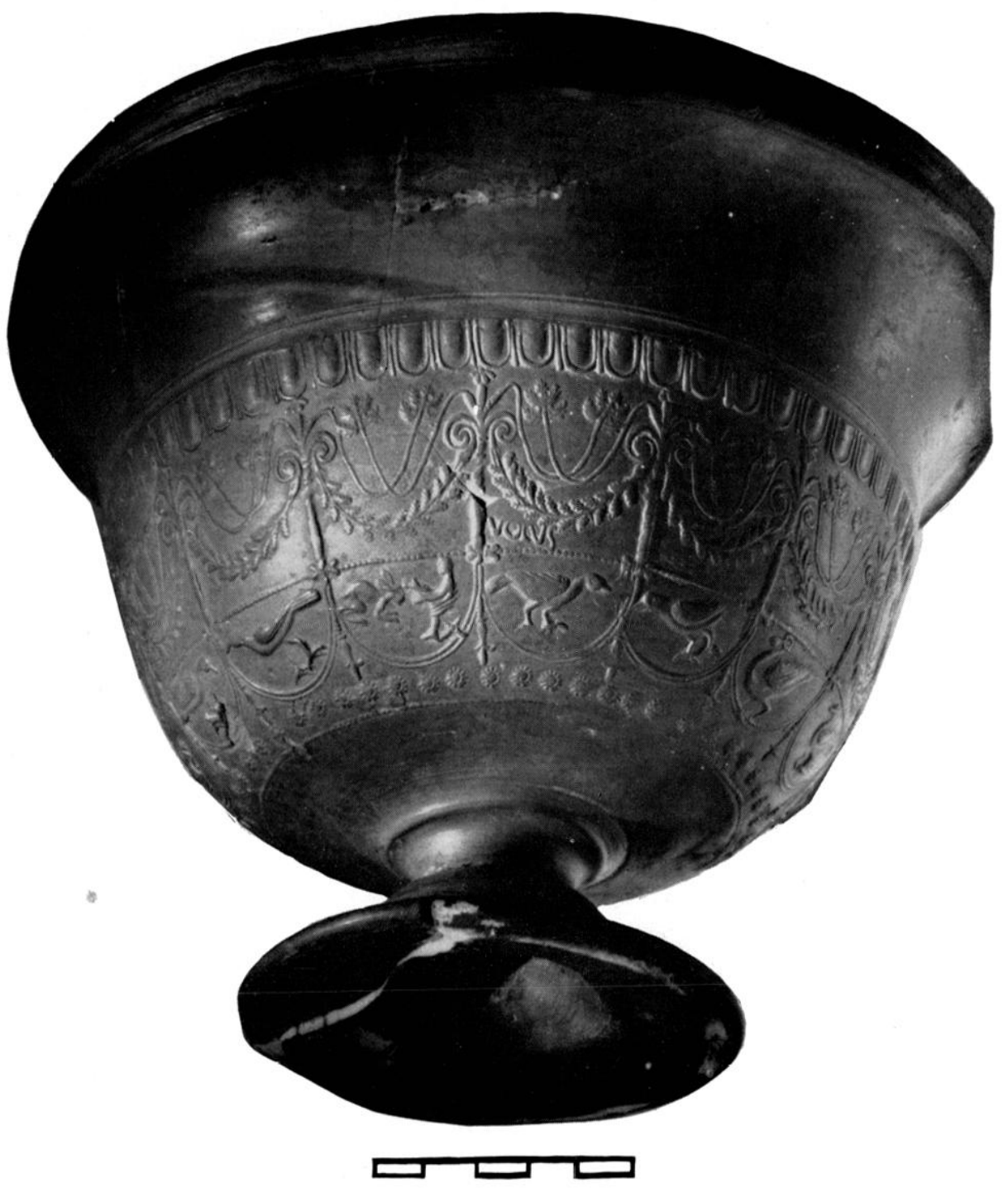

Fig. 5. - Vase du potier Volus. On voit la signature de lartisan a mi-hauteur de la panse no l, serie l3.

calement par des ornements complexes dont le sommel porle un fleuron el des volutes lerminées par des libes de ranards fou de dauphins : Hermel 17. Ces animaux liennenl dans leur bee les extrémilés de larges quirlandes, au-dessus desquelles se robisent les liges de feuilles finement decoupees. I)ans une zone inférieure délimitée par une fine ligne pointillée. des demi-médaillons contiennenl des animaux : volatiles, petits lapins ${ }^{18}$. auxquels

(17) F. HERMET, La Ciraufesenque, II, pl. :2, $n^{\circ} 22.1$ : pl. 35, nos $35-36$.

(18) Dichlitetre, lases ornés...., II, no 944 ; oswatb, Index of Figure-lypes on Terra sigillala, s'ajoule un pelil homme assis sur un siegere. Déchelelle n'a pas représenté sur ses dessins le motil a lete de canard ou de dauphin, qui semble avoir echappe a ceux qui ont lravailé seulemenl d'apris lui. Il nous parait interessant de noler que ce molif rurieus aura une vogue durable. On le relrouve, évolue, che\%, Cermanus au lemps des Flaviens' ${ }^{20}$ : l'animal se lermine

$\mathrm{n}^{\circ} 9040 .-1$. К Конк, Töpfer und Fabriken verzierter lerra sigillata des ersten .Jahrhunderts, 1919, pl. 8.1. $n^{\circ}:$ :

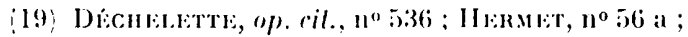
Oswald, no 921. Cf. ici figr. 5, en bas a gauche.

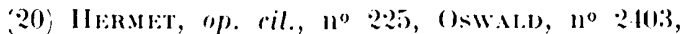
R. Кхонк, pl. 36. 
alors par deux vohules ou un fleuron. el s'aceole souvent a des arceaux feuillus, soutenant ausid parfois de sa bouche des equirlandes. On l'a relrouve bien plus lard. au me sicele, an boul d'une fibule signese Herr. dans le Trésor de T'énes l Morérie ${ }^{21}$.

I e décor de la coupe 11 de loblus est délical. mirulieux. Les poincons. de petile taille. onl été imprimés avec soin. à des profondeurs régulieres. Le tout forme ainsi. dans un syle préciesux, un décor de fele champetre. oi

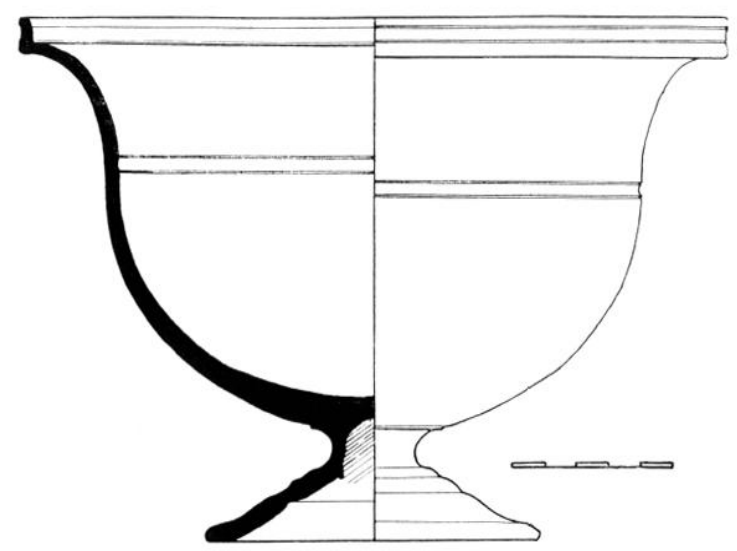

Figr. fi. - Profil du vase de folus no 1 , serie 13 .

différents oiseaux. gardés par un nain qui dialogue avec un lapin aussi gros que lui, sont dispersés sous une colonnade légere, décorée de quirlandes. Une ligne pointillée rejoint chaque support. atlaché chaque fois par un petil nomul.

Ce rase rontient déja les éléments caractéristiques du bel art ruthene, qui fleurit dans celte période que l'on a justement appelée "de splendeur" (30-45 ap. J.-C.). Line des raisons majeures qui avaient incité I)échelelle a situer celte coupe a une date plus précoce est son profil. En eflel, on a fabriqué a Arezzo beaucoup de formes 11 que l'on a imporlées en Gaule sous Auguste. Comme celle-ci, Irouvée à Roanne, étail, à peu près, la seule connue pour ètre fabriquée dans notre pays quand le savant archéologue écrivait sa magistrale étude, il avait conclu qu'elle étail

(21) J. Hr:Raox, Le trésor de Ténes, pl. XIL et XIII. - H. VERTET, En trésor d'orfétrerie du IVe siecle dans R.A.E., X, p. $34 \cdot 4-347$. le temoin exceptionnel d'une influenere directe. el vile eltacere. de l'ltalie sur les fabriques muthenes. Nais les décomvertes ultériemess à ses bludes onl montré que la fabrication des vases caliciformes avait continue fort longlempes al que la forme en elle-meme n'est pas un rrilere rhronologicque certain. L'abbé Hermet a trouvé dans ses fonilles des aleliers du bord du Tarn plusieurs fragments de crateres dont l'un est nellement du style du polier Ciermamus ${ }^{22}$. c'est-it-dire d'époque flavienne. (On ext dome amene a conclure que les arlisans rulhenes ont eonlinué a lanire quelques exemplaires de ces vases pendand presque toule la duree du ger siecle. Entin nous ne pensons pas que l'hypothese de léehelelle, supposant que le nom de lolus pûl êlre en relation aree celui

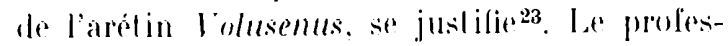
semr senico considere ce rapprochement eomme lres douleux. En effel nous ne sarons rien de la fréquence des noms antiques, conmaissant a peine celle des noms modernes. el l'art du vase de Volus est treséboigne de celui des artistes it aliques.

1)aulres vases 11 anterieurs à cene de Volus onl éte trouves, nolamment, a Bregent Autriche 24. Ils sont bien plus proches des modeles arétins que lui, el en mème temps allestent déja cependant une interprélation provinciale. On remarquera que plusieurs portent des oves longues, utilisées par les potiers italiques ${ }^{25}$. Hilles n'ont pas vécu longtemps en Gaule; nous les reverrons lout à l'heure sur les vases 1 el 2 de Lezoux, dalés. pensons-nous, de la fin du regne d'Auguste ou de celui de Tibère. Mais re n'est point là un crilere absolu de précocité, car les vases d'Arezzo présentent aussi des oves larges. Nous attirerions plutòt l'attention sur l'ensemble du décor des rases de Bregenz. plus aéré et plus simple que celui de l'olus. Il contient aussi des éléments proches de ceux qui caractérisent l'art de la période primitive de

(22) HERMET, pl. 98, no 15, p. 156.

(23) Déchelétte, I, p. 68.

24. R. KXorr, pl. 1 à 4. A. Oxé, Frühgallische Reliefgefässe vom Rhein, dans Malerialien zur römischgermanischen Keramik, 6, 1934.

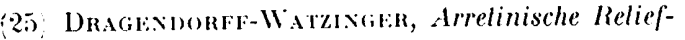
lieramik, fig. 1, p. 18. 


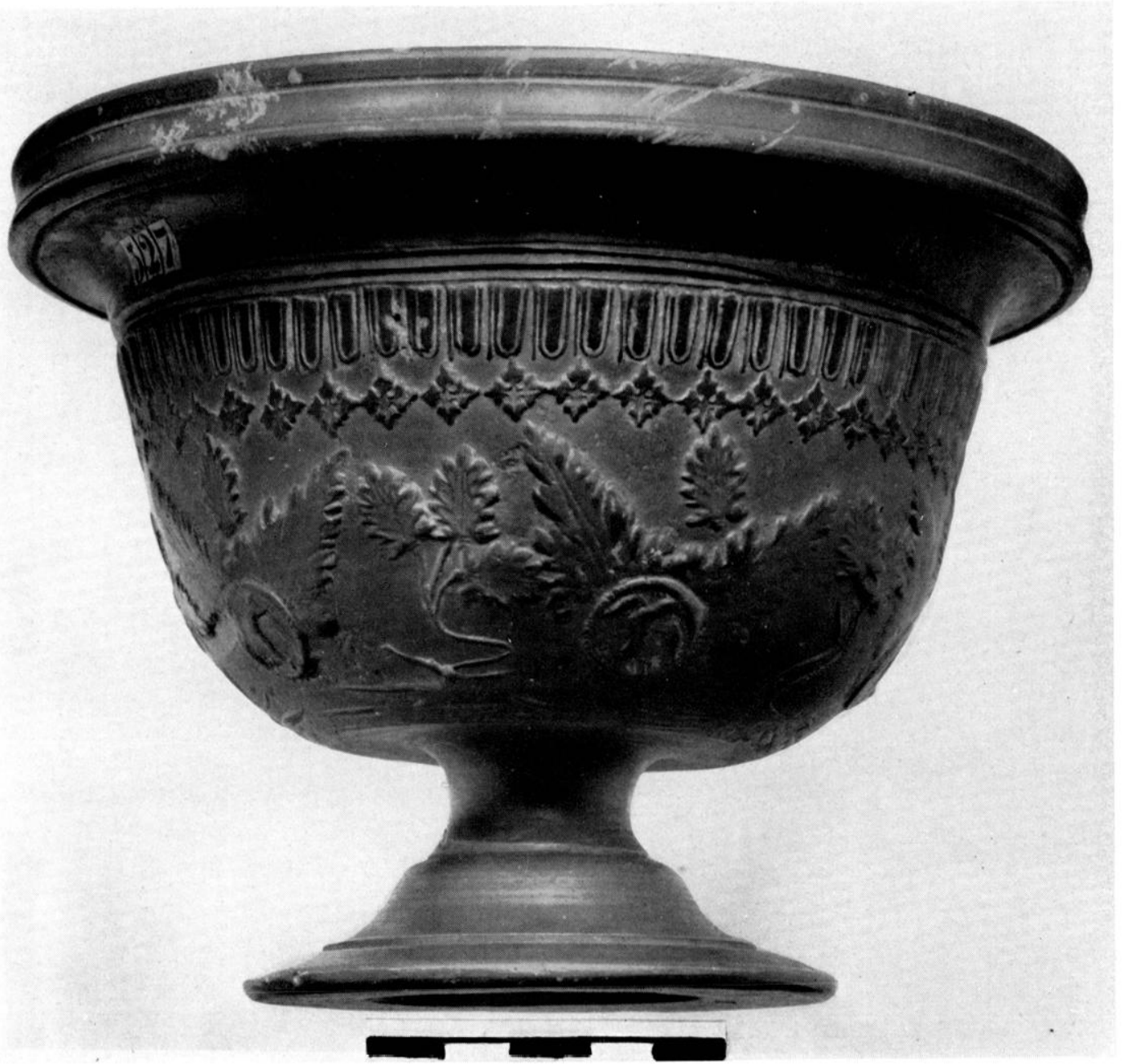

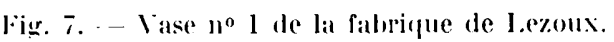

La Craufesenque, diflérents de ceux de la période de splendeur : les quirlandes bifoliées. les lignes de gros points, les godrons en forme de crosse de fougire avec des appendices, des rinceaux laroes et libres.

L'abbé Ilermet doutail que celle série eùl été fabriquée à La Graufesenque. parce qu'il n'avait pas trouvé de documents semblables dans ses fouilles ${ }^{26}$. Lin réponse a cela, nous suggérerions que les aleliers ef les dépoloirs primitifs, peu importants, ont pu disparaitre sous les constructions ultérieures, qui devaient prendre Lant d'extension dans la pelile plaine, au confluent du Tarn el de la I ourbie. Cela pourrait expliquer que l'on ail peu de vestiges

(26) H1:MLT, P. 270. a recueillir sur l'emplacement des aleliers. I lezoux. il semble. pour le moment. en ètre de mème. I'ensemble des vases 11 trouvés a Roanne est plus important que ce qui a été trouvé à Lezoux. ou furent rependant les labriques.

Jo vase de lolus s'inliogre donc dans un ensemble qui comprend des documents anterieurs el postérieurs el nous le placerions à la fin du regne de libere. ou au débul de celui de Claude.

C. Vases de Lezoux. - o 1 (fix. 7.8 el 9)..Provient du quartier des casernes. Roanne. Musee de Roamme. no 527. . Bibliographie: J. DÉchestetre. lases orness de la ciaule romaine. 1. 1. 24, fig. 7 ef p. I80. 1. Oxi: Frïhgallische Reliefgefüsse rom Rhein. 1934. 


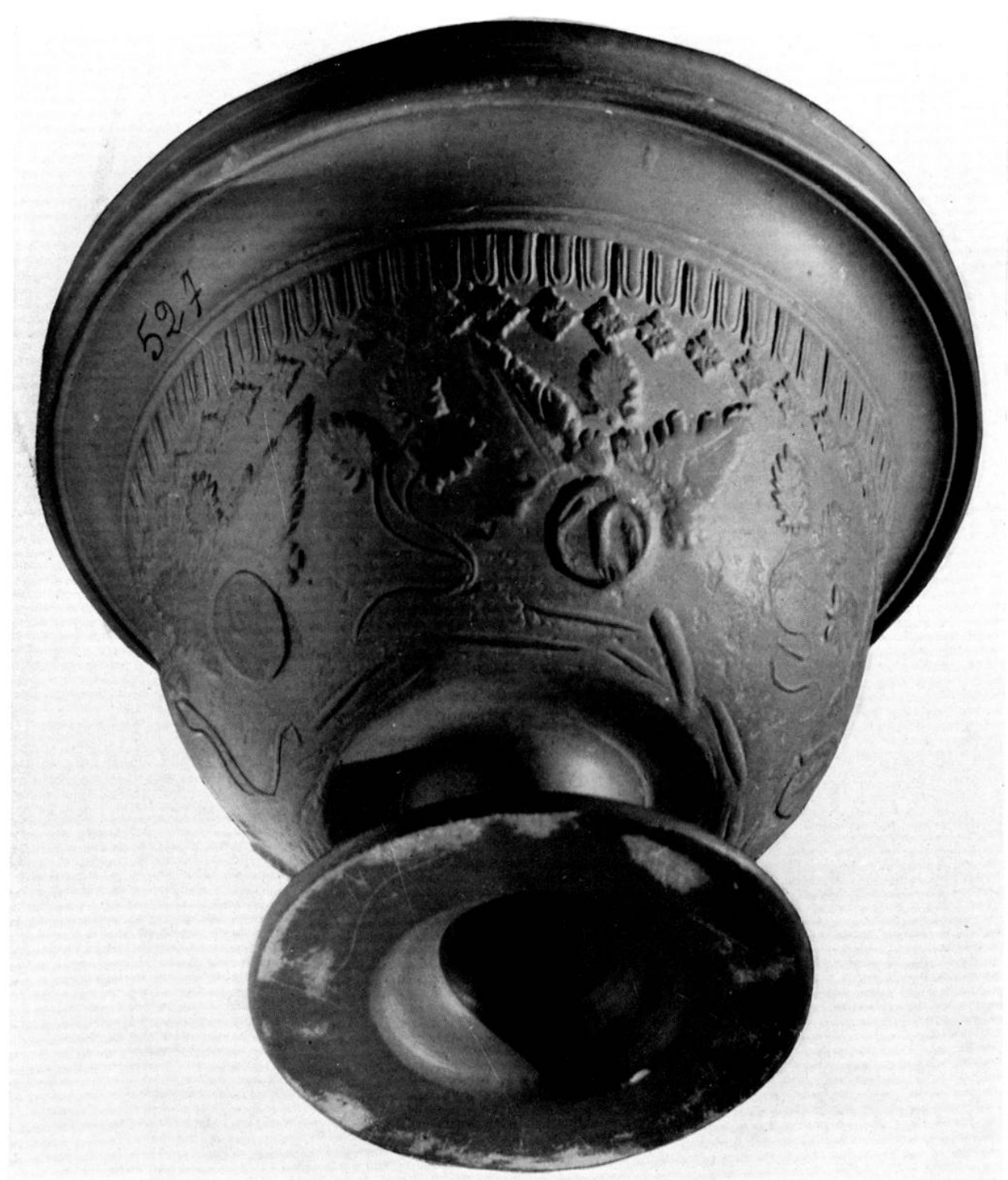

Figr. S. Vase $n^{\circ} 1$, série $($. de la fabrique de Lezoux. On voit ici les ornements en forme de pétales qui entourent le bas de la panse, et qui se retrouvent sur le vase n" 3, fig. 14 .

Arturo stwico. Revisione crilica delle Pubblicazioni sulla ceramica arrelina. p. 23. $\mathrm{n}^{\mathrm{o}} 141$.

Vernis lisse. rouge terne, plus clair que II 26 ; la couleur de la terre est peu visible. IDimensions: hauteur $11 \mathrm{~cm}$. :) ; diamètre : $18 \mathrm{~cm}$. 5. Le pied est brisé, il a été reconstitué en plâtre et peint. La panse est intacte. Le décor est complet.

Au-dessous d'une bordure d'oves allongées. el d'une ligne de petits ornements cruciformes en losange. sonl disposés einq bouquets de feuilles. Au bas de chacun d'cux se trouve un

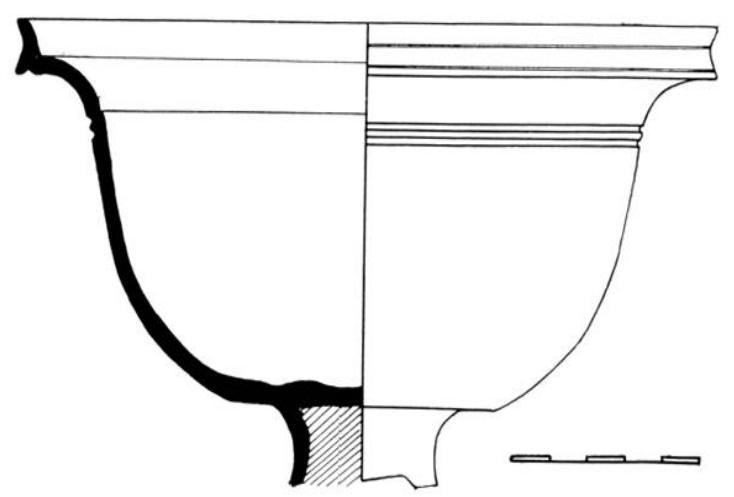

Fig. 9 -- Profil du vase no 1 , série $(.$. 


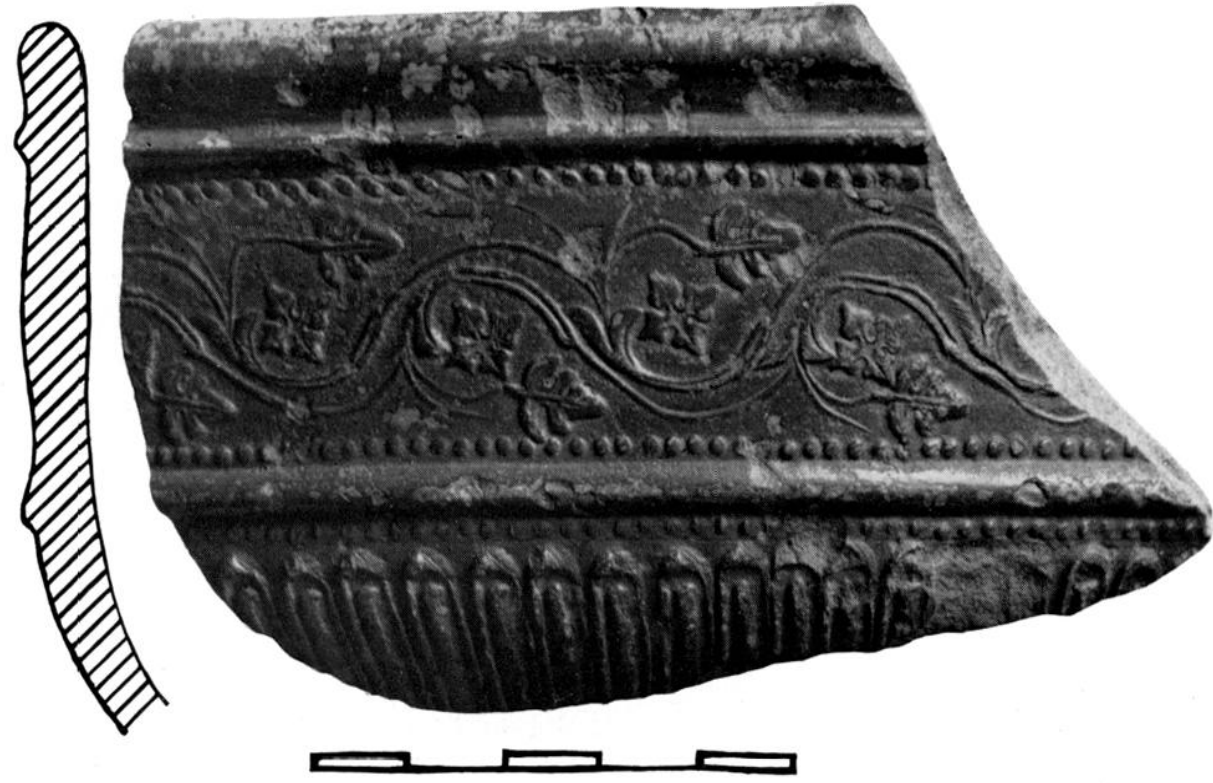

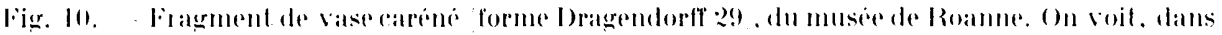

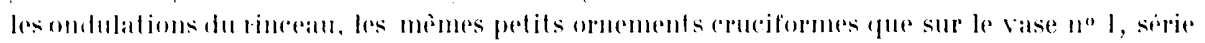

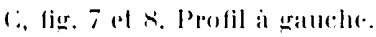

médaillon conlenanl un aighle aux ailes éploỵés. Déchelefle a pensé recommaîle dans ce relied une monnaie d'Augusters. Xous en avons emvoye photographie ef froltis au Cabinel des médailles de la Bibliotheque nalionale. mais aurume identilicalion précise n’a pue itre frouvere Linlere res molifs. se dressent sur des liges ondulees des grompes de deux ou trois feuilles. du meme poingon-matrice que celle qui est au centre du bouquel. Enfin, une couronne de motifs allongés. que nous comparerons a des pélales de marquerite. entoure le pied.

I)échelelle avait pensé que re vase provenail des aleliers arélins ${ }^{28}$; il est lrés dittérent en oflel desproduils lédosiens habiluels. II. Stenien signale n'avoir rien renconlró de semblable. dans ses eludes sur les vases ilaliquesere Oxe l'altribue aux officines ruthemes ${ }^{30}$. Ce valse a été en réalile labriguo dans les olficines arvernes. Le molif aruciforme de la bordure supérieure se relpouve produil par le meme

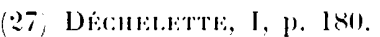

(28) Ibid., 3. 24.

(29) A. Stwico, Revisione rrilica..., p. 2:3, 10 141.

(30) A. Oxí, Frühgallische Reliefgefässe rom Rhein, 1931. poincon-matrice. sur deux fragments de vases Dragendorff 29 de la fabrique de Lezoux. lous deux inedits. Nous avons lrouve le premier dans les reserves du Musce de Roanne. son origine est inconnue, mais il provient vraisemblablement. ou des fouilles de J. Décherlella a Roanne. ou de ses achats a Lezoux. C'est dans les rinceaux lo la frise quapparaisient les motifs cruciformes, entre les feuilles el les allaches des pélioles (fig. 10). La panse est ornée de godronsetroils el serrés. I a moulure qui sépare les deux registres du décor est bordé de deux lignes de points tries fins. le rebord est elroil el vertical el ne comporle qu'une seule moulure. En aulre lesson de la rollection fabre a la fagere. trouve a Lezoux. présente le mème profil. el la mème frise, où mangue seulement te motif eruciforme.

l!n second fragment de vase :29) (fig. 11 porte aussi le motif eruciforme. Il a ble lrouve aussi a Lezoux el a elé donné au musée local par V. Gerjon. pharmacien. I a frise presente dans ses rinceaux la mème feuille que les deux fragments decrits ci-dessus. la mème allache de pétiole. une feuille tres stylisere et deux lypes de fleurelles. C'est sur la panse que l'on voit le motif qui nous intéresse entre deus 
fléments complexes: deux larges feuilles sépalent de pare el d'aulere d'un malsque. All-dessous patrent en obligue. de charque roté deux ormements vrilles. Cés assemblages rappellent cence de la coupe de forme 11 que nous éludions, mais aussi ceux qu'ont employé plusieurs potiers arétins comme Heius. ou Bargat thes. Ces fragments de vases carénés. forme Dragendorfl 29). appart iennent à une production tris précoce des oflicines arvernes. Leur forme, aver un rebord droil étroil el renflé. leur paile souvent peu cuile. grise. saumon ou blanchitre. leur vernis rouge peu brillant el fragile. ou orangé ol mal. les caraclerisent bien. comme nous te reverrons plus loin. On remarguera que le lesson du llusée de Lezoux ne comporte pas de ligne pointillée autour de la moulure centrale. a qui arrive parfois sur les vases arvernes de celte époque.

Le vase 11 al les l rois moreaux de coupe 29 dont nous avons parlé sont de la main du mème potier. On pourrait penser qu'il s'agit d'Alepomarus. mais nous conclurions plutol at un autre artisan car aucun des petits poingons-matrices que nous avons releves ne se Irouve sur les vases que nous connaissons de cet artiste. La similitude des styles nous incite rependant a supposer les deux hommes de la mème école, forlement influencée par l'arl arétin.

Ainsi le vase 11 de Roanne présente-t-il des raractires stylistiques de l'Italie el de la Gaule. Les oves longues sont proches de celles de certains potiers d'Arezzo, et extrèmement rares dans les productions de la Gaule, mème précoces. Les bouquets de feuilles qui prennent naissance autour d'une empreinte de monnaie se trouvent che\% le potier C. Cispius par exemple ${ }^{31}$. En revanche, les petits motifs géométriques trouvent peul-être leur origine dans certains décors arétins, mais aussi peutitre dans le génie celtique. Ils sont si habituels sur les premiers vases de Lezoux, chez Alepo-

31 Strisco, Il raso pseudocorneliann con le monele - Copera di C.. Cispials, dans Archeolugia classica, VIII, 1. p. 66-74, pl. XXXi-XXхvII.

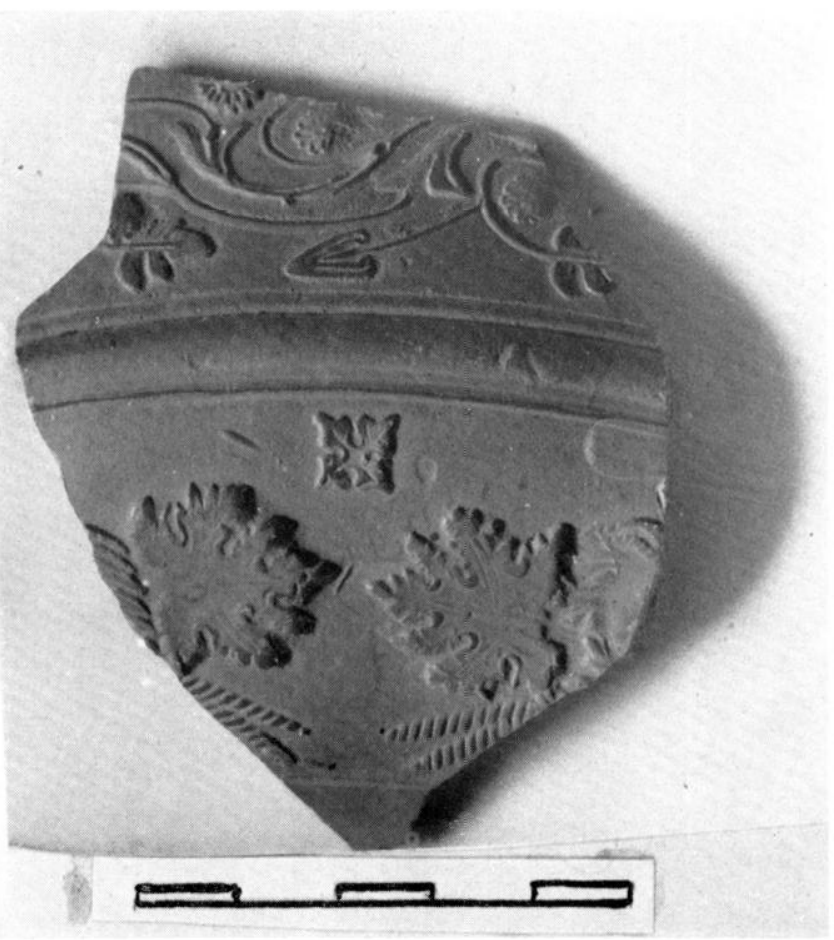

Figr. 11. Fragment de vase 2!), musere de lozoux (Puy-deDòme. Sur la panse, mêne ornement cruciforme que sur les figr. $7-\not-] 0$; masque entouré de feuilles de vignes assembles dans le même slyle que la monnaie et les feruilles sur le vase $n^{0} 1$, série $C$.

marus par exemple. qu'ils sont considérés comme une caractéristique du style de celte officine. Quant a la faron dont sont disposiess les feuilles entre les bouquels, elle nous parail bien wallo-romaine. Elles sont groupées par deux ou trois suivant la place inégale qui leur est laissée. On retrouve. sur quelques vases précoces de Lezoux ou de Siant-Rémy-enRollat. des tiges contourrées de la mime façon que les leurs. dont les jonctions. sans ligature ni ornement, sont bien différentes de celles de la Graufesenque. L'enlassement un peu maladroit de ces motifs, le tracé a main levée des tiges qui ne rejoinl pas exactement la base de la feuille imprimée ( $\mathrm{f}$. fig. 7 ). montrent que nous avons déjà là une interprétation provinciale du décor ilalique. peut-être une tradition locale qui ne semble pas exister sur le $\mathrm{n}^{0} 2$.

So 2 fig. 12 el 13. Provenance: "Roanne. mais je n'ai pas la certilude complite que ce soit dans le cimeliere du quarlier saint-Jean " 

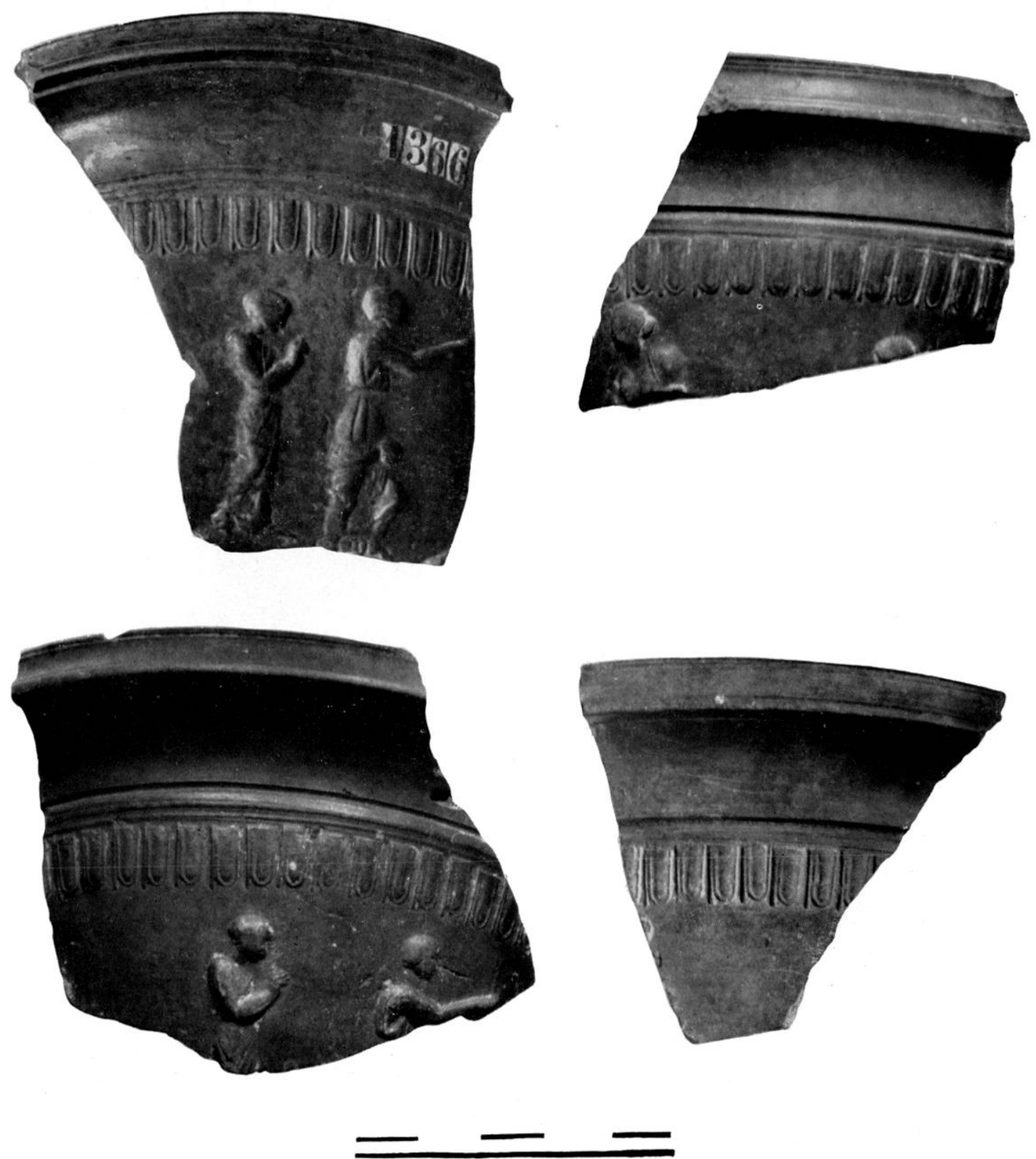

Fig. 1:. Vase no 2 de la série (: Lezoux. Quatre fragments reprisentant deux fois la mème scine. Sur le fragment en bats a gatuche, on apereoit les objets que le personnage fiminin tient dans sa main tendue.

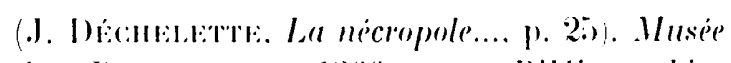
de Roamme, no lisici. . Bibliographie:

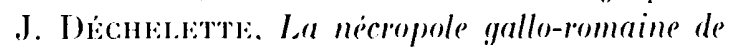
Roanne. p. 25 el p. 26. fig. 12; Tases ornes de la Gaule Romaine, I. p. 2). lig. 8. 1. S̈Trenico. Revisione... p. 23. no 142.

Vernis assez lisse, l: 12, plus clair. Ia rouleur de la terre est beige rosée. Dimensions. probables : hauteur : $9 \mathrm{~cm} .8$; diamètre :
19 rentimetres. Il reste qualre fragments de la panse, rien de la base.

Ce vase a élé allribué aussi à Arezo par léchelelle. Le professeur stenico ne le reconnail point pour arélin. I'aulres archéologues l'ont altribué à des oflicines mal connues du Nord de l'Jlalie. En raison de son decor. a grands personnages. Iress aére. nous aurions beaucoup hesité a l'allribuer aux aleliers 
arvernes. si les oves n'étaient point tris exactement les memes que celles du no 1. el la rouletle qui les a passees tres proche. si ce n'est la même. (On sail en effel que les roulettes d'oves sont composées la plupart du temps en estampant le pourlour d'un petit rylindre d'argile crue avec un poinçon-matrice comportant une seule ove, motif facile a réaliser pour le potier le plus inexpérimenté. On a donc la une oruve personnelle. aussi bien dans le dessin que dans l'écart plus ou moins grand mis entre les impressions. (On admet que chaque artisan ne voulait point acheter un outil si facile a faire. et que la roulelle d'ove était un objet personnel a un décorateur de moule. ou toul au plus a une équipe. s'il travaillail avec des compagnons. Xous avons donc fail des frollis des oves des vases 1 et 2 avec du papier de soie et du graphite en pailleltes : chaque ove est exactement superposable d'un vase a l'autre. On est donc amené i conclure que l'auleur du vase no 1 est le mème que celui du vase no 2, ou. loul au moins. a I ravaille dans le mème alelier.

l'apres les morceaux lrouvés. le pourlour de la panse comprenait. Irois fois répétée une scine a trois personnages féminins drapes, el que l'on peut supposer identique. I gauche. une jeune fille probablement. le visage baissé. le bras droit léchi. la paume en avant, dans un geste d'adieu, de supplication ou de refus. suil, semble-t-il, une femme plus crande qu'elle. Celle-ci tend son bras vers un Iroisieme personnage situé plus haul que les deux premiers, ou plus grand, el placé de troisquarts. Sa main offre un ou deux objets peu distincts car leur relief est tres faible : tige verticale bifide et feuille ou flamme (?). Il est difficile d'interpréter la scine. Avons-nous une scène d'adieu. de retrouvaille, de supplicalion?

L'influence italique est tris nette dans la beauté des reliefs. Le drapé, les proportions. les gestes. rappellent très précisément des figures arétines, comme celles de $M$. Perennius. ou Rasinius ${ }^{32}$. Le répertoire des artistes d'Arezzo est bien fourni en figures féminines

(32) A. STExico, La ceramica arrelina. I, Rasinius, $I$, Collana di testi e documenti per lo studio dell'antichita, $n^{\circ} 4$, p. 54.

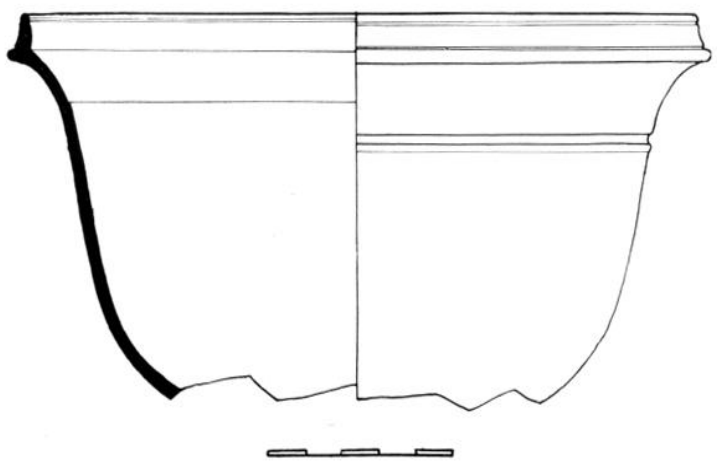

lijo. 13. - Profil du vase no 2, série C.

dans l'altitude où l'on voit notre deuxiéme personnage : elles cueillent des raisins sous des pampres placés plus haul qu'elles. Il est interessant de noter que les reliefs des trois figures sonl assez flous. comme si les poinçonsmalrices utilisés par le décorateur élaient usés el émoussés. ou eslompés par le surmoulage. Ies oves au contraire ont un dessin tres nel. Cetle différence pourrait suggérer que les poinçons-matrices proviennent d'Italie ou d'artisans italiens de passage a Lezoux et qu'ils n'ont pu être remplacés par les artisans gallo-romains. Mais nous pensons plutò qu'ils ont élé surmoulés sur des vases importés. Cela expliquerait le flou excessif du relief el la petitesse des personnages par rapport à ceux qui s'en rapprochent le plus. sur les vases arétins. Nous verrons que l'élude des vases i) of (i nous amene aux mimes conclusions. Au contraire. la rouletle d'oves a été fabriquée par un potier local, ce qui étail beaucoup plus facile. Ce vase étonnant est comparable, par son st yle aéré el par ses personnages a plusieurs vases fabriqués en Ilalie. Mais. d'apres le Pr. Stenico, il ne pourrait ètre confondu avec un vase d'Arezzo car on ne connail rien de semblable dans la céramique arétine.

No 3 (fig. 14 et 1:). Provenance: Roanne. nécropole, rue Saint-Jean. Musée de Roanne. no 5001. - Bibliographie : néant.

Pàte blanchâtre. micacée. surface brûlée. Le vernis, très mince. est parti sur de larges zones. Dimensions en profil : $6 \mathrm{~cm} .5$.

Le décor comprenail plusieurs zones: il ne reste que celle du bas, ornée de fleurettes a huil pétales réunies par des tiges filiformes 


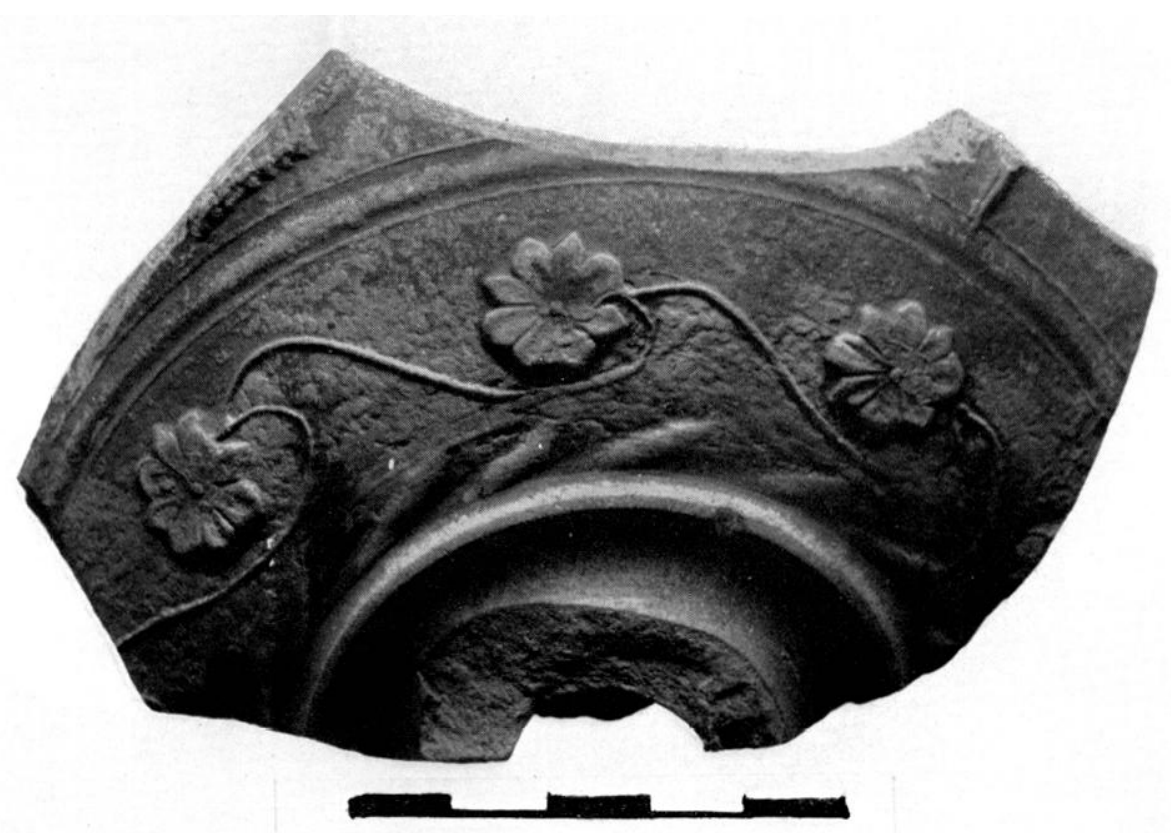

liig. 11. Vase $\|^{\circ} 3$, sirie g, portant les mèmes ormements antour du pied que le no 1 .

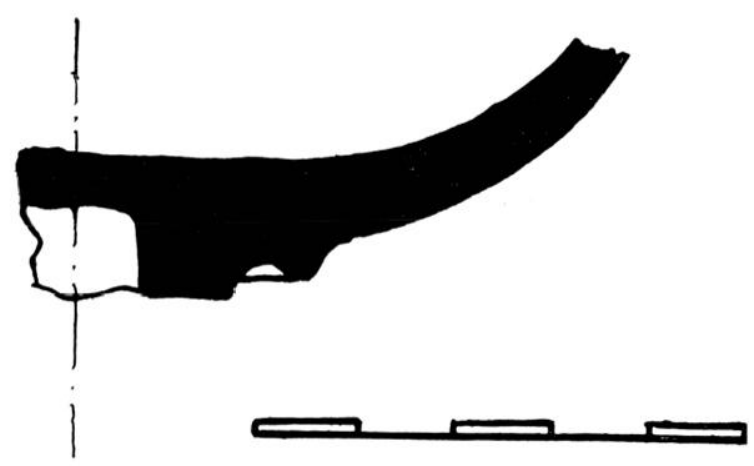

Jïg. 15. - Profil du vase no 3 , série $(:$.

sans feuilles, qui s'allongent en forme d's constituant une espece de rinceau. Au-dessous, un semis de pélales de marqueriles permel d'altribuer ce vase au mème polier que le no 1 . Au-dessus, une moulure assez large. mais peu bombée, sertie de deux filets. sépare la zone inférieure de la zone supérieure. Il ne reste de celle-ci aucun élément identifié. Le bas de la coupe est comme soutenu par une petite plate-forme ronde, un anneau plat. Il ne nous semble pas que l'on retrouve ceci sur les vases arétins, mais on le voit sur les coupes d'argent a Boscoreale, par exemple; c'est peut-ètre cela qui a sưgóéré au potier l'idée de donner cette forme alu renforcement de son collage. On voil le mime procédé sur les nos 4 et 7 de notre série. La ravité intérieure du pied a alors une forme cylindrique, romme si elle avail été ménagée avec un mandrin. L'ensemble du decor est trop insuffisamment conservé pour que l'on puisse peser l'influence ilalique. On trouve évidemment sur des crateres d' Heius celte bande légèrement bombée qui sépare le décor en deux parties, mais elle est placée beaucoup plus haut. On trouvera un bombement idenlique sur notre $n^{\circ} 8$, laissant une zone inférieure plus large aussi. la décoration étant conçue comme celle d'une coupe I)ragendorff 29. Le style de la partie conservée nous paraît plus gallo-romain qu'ilalique : la lleur rappelle celle qui orne les vases sorlis des ateliers de saint-Rémy, Ciannal. Vichy; on trouve aussi, dans les mêmes fabriques, les fleurs et les feuilles réunies les unes aux autres suivant ce procédé original, bizarre el caractérislique, qui donne à chacune d'elles un double pétiole.

No 4 (fig. 16 et 17). - Provenance probable: Roanne. Musée de Roanne, no 5002. -C Bibliographie: néant. Terre grisâtre, couleur de la surface II 28. 


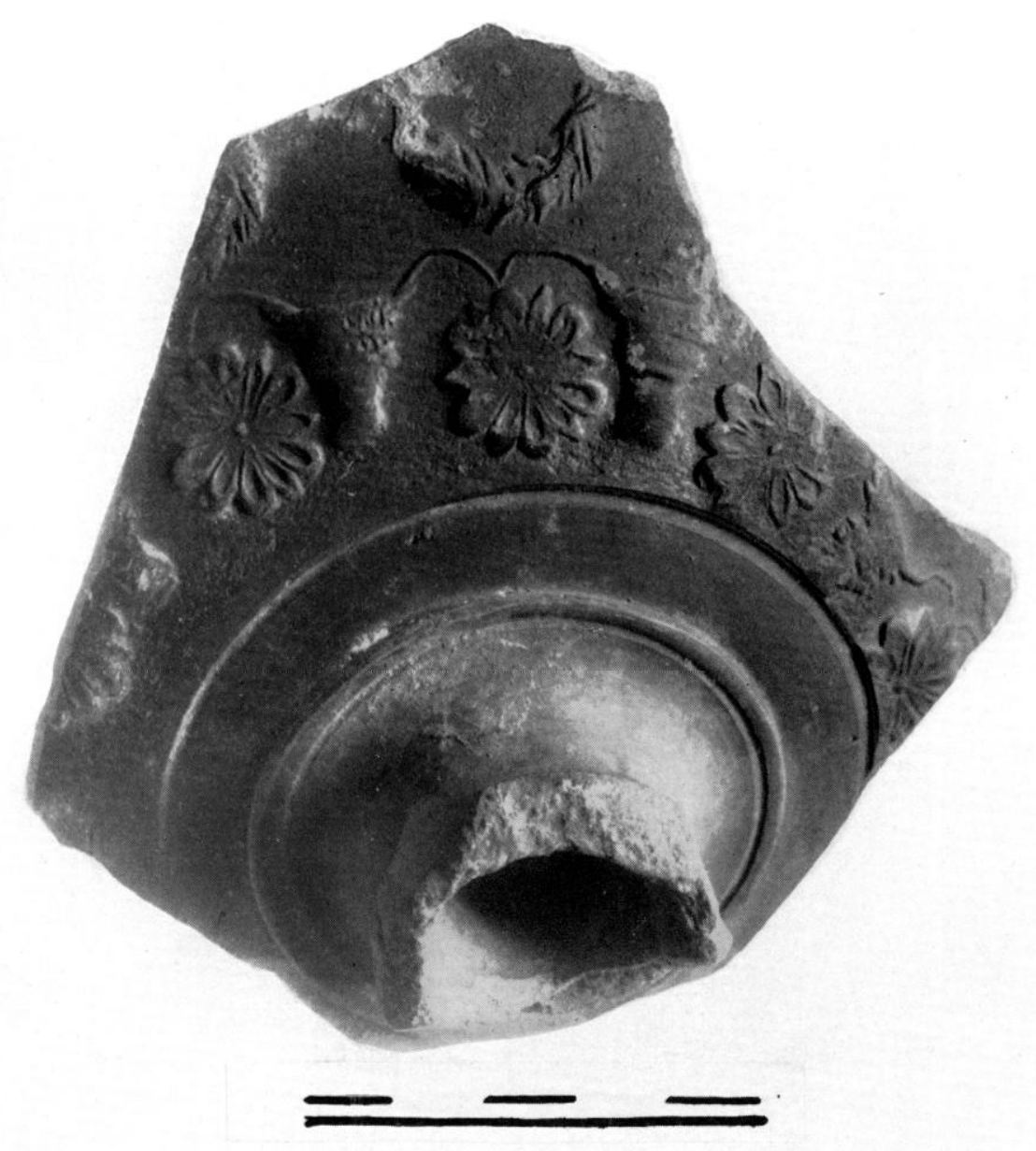

lïg. 16. - Vase $n^{\circ}$ 1, série $(\therefore$ Le haut du pied est entouri d'un anneau comme les nos 3 et 7 .

Le décor comprenail plusieurs zones. Celle du bas présente des bucranes alternant aver des lleurs, des margueriles peul-itre. Ces deux éléments sont reliés par des arceaux tracés à la pointe dans le moule, passant des fleurs aux cornes des taureaux. Ce décor curieux. chaque fleur ayant ainsi une double queue. nous incite à attribuer ce vase au mème potier. ou à la même école que le précédent. Iu-dessus. devait courir une frise de palmes concaves dont il reste un exemplaire complet. mais peu net. Les bucranes sont fréquents dans l'art augustéen, dans la sculplure. la toreutique, la céramique d'Ilalie... Ils apparaissent dans la terre sigillée du sud de la Gaule chez Ingenuus (Tibère-Claude), auteur de vases $11^{33}$, puis ils disparaissent rapidement pour ne refaire qu'une courte apparition à la fin du

(33) R. Kxorn, op. cit., pl. 11, no t5.

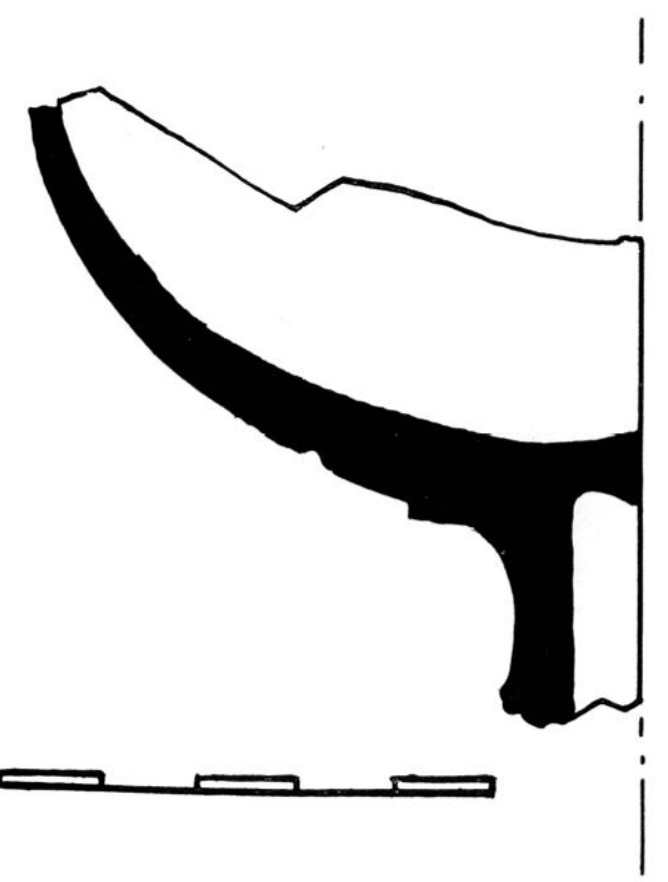

Fig. 17. - Profil du vase $n^{0} 4$, sirie $C$. 


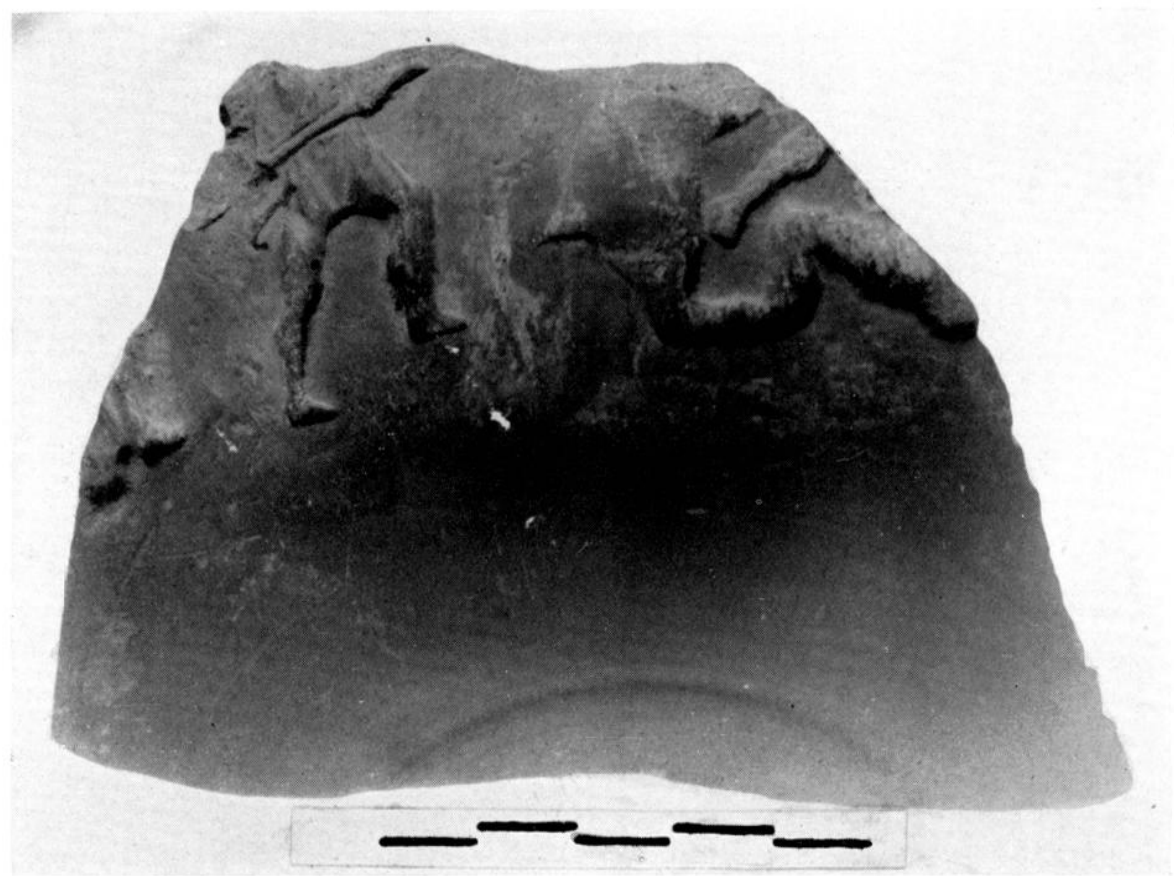

Figr. Li. Vase no 5, série $($. De granche à droite : pieds d'un persommage, chasseur marchant vers la droite, tenant un apieu; ours dressé sur ses pattes arriore; personmage a torre, dont on ne voit que les jambes nues.

ne sirele ${ }^{34}$. Cósl la premiere fois que ce décor est signalé sur la céramique de I.e\%oux.

A Arezo. nous avons relevé. sur une frise du potier Rasinius I. placée au-dessous du décor comme sur notre vase. une suite de bucranes allernes aver d'aulres ormements 35 . Malheureusement, le morceau de moule qui les porte est brisé, et il ne reste, des molits intercalaires. que de loules pelites rosaces. Mais on voit que le thime était connu des potiers arétins. Cependant les liges en arcade et les fleurs sont tout a fait dans le style des productions en lerre blanche des aleliers de la région Saint-Rémy-en-Rollat. Vichy, Gannal. dates de Claude, de Tibere, ou même de la fin du regne d'Auguste.

No $)$ (fig. 18\%. - Promenance tres proche, par son aspect et sa conservation, du no 6 ; provient probablement du même sile de Roanne. Musée de Roanne, no 5004 -... Bibliographie: néant.

(34) Oswaı.1, Index of Figure-lypes..., no 1891 a : Aquincum, fin du " $^{\circ}$ siècle, style de Pacalus.

(35) A. Strixico, La Ceramica arretina..., pl. :2t, n० 115
Couleur extérieure F 16-18, intérieure, F 26.

Le décor représente une scine de chasse. I gauche un rhasseur s'avance avec un épieu qu'il lient horizontalement. Derrière lui se voit le pied d'un autre personnage qui marche dans la mème direction. Jevant le premier, un ours dressé a terrassé un homme qui essaie de repousser le fauve de sa jambe droite, qu'il live contre le ventre de l'animal tandis que sa jambe gauche repose a terre. Le chasseur est vètu d'une tunique a larges plis raides qui lui descend au genou. Landis que celui qui lache de se relever paraît nu.

Celte scrine a son équivalent direct dans la céramique aréline. Nous avons reproduil, pour montrer combien cela est frappant. un tesson inédil conservé au Cabinet des médailles de la Bibliothicque nalionale (fig. 19). On peut l'altribuer au polier $M$. Perennius ${ }^{36}$, qui

(36) A. STwXu:o, Ceramica a relievo della coll. I'isaniIossi..., frag. no 16, pl. 1. DRA(iFNDORFF-WATZINGE, op. ril., p. 95, fig. 12. Nous remercions vivement .I. Le Rider, Conservateur du Cabinet des módailles, de nous avoir permis d'éludier et de publier ce beau fragment. Le vernis est rouge tres brillant, et les motits d'un tries bean relief. le lieu de trouvaille est inconmu. 
lijg. 19. - Fragment d'un vase arótin conservi dans les réserves du cabinet des medailles Bibliotheque nationale . les personmages sont disposis de la mime facon que sur le vase $n^{0}$ 5, fig. 18 .

a travaillé sous le rigne d'Auguste. I a scine est la mème; on voit le mème chasseur. la jambe en avant. allaquant l'ours par-derrière avec son épieu horizontal. Le fauve est dressé au-dessus d'un homme tombé à terre el qui essaie de se défendre. La similitude dans la position des personnages, leurs gestes, l'homme a terre nu. celui qui va à son secours vêtu. l'ours qui se dresse, montrent qu'il y a eu non seulement inspiration directe, mais copie fidèle dans la mise en place de la scéne. Cependant la maladresse est nelle, et l'ensemble moins lié.

Ia forme de la panse, sans moulure à la base. est de tradilion nellement ilalique. de mòme que l'ordonnance du décor. qu'on appellera plus tard "décor libre". par opposition aux surfaces découpées en métopes. Nous ne voyons, dans ce qui a été publié des ornementations de la Ciraufesenque ef de Lemoux, rien de semblable au I $^{\text {er }}$ siecle.

No 6 (fig. 20). - Provenance: Roanne. "Les cotes" : don de M. Bertrand. Musée de Roamme, no j003.3. - Bibliographie: néant.

La pâte est beige rosée, le vernis, rouge rosé II 26 . Ie vase ou le lesson, a elé brule vers le 


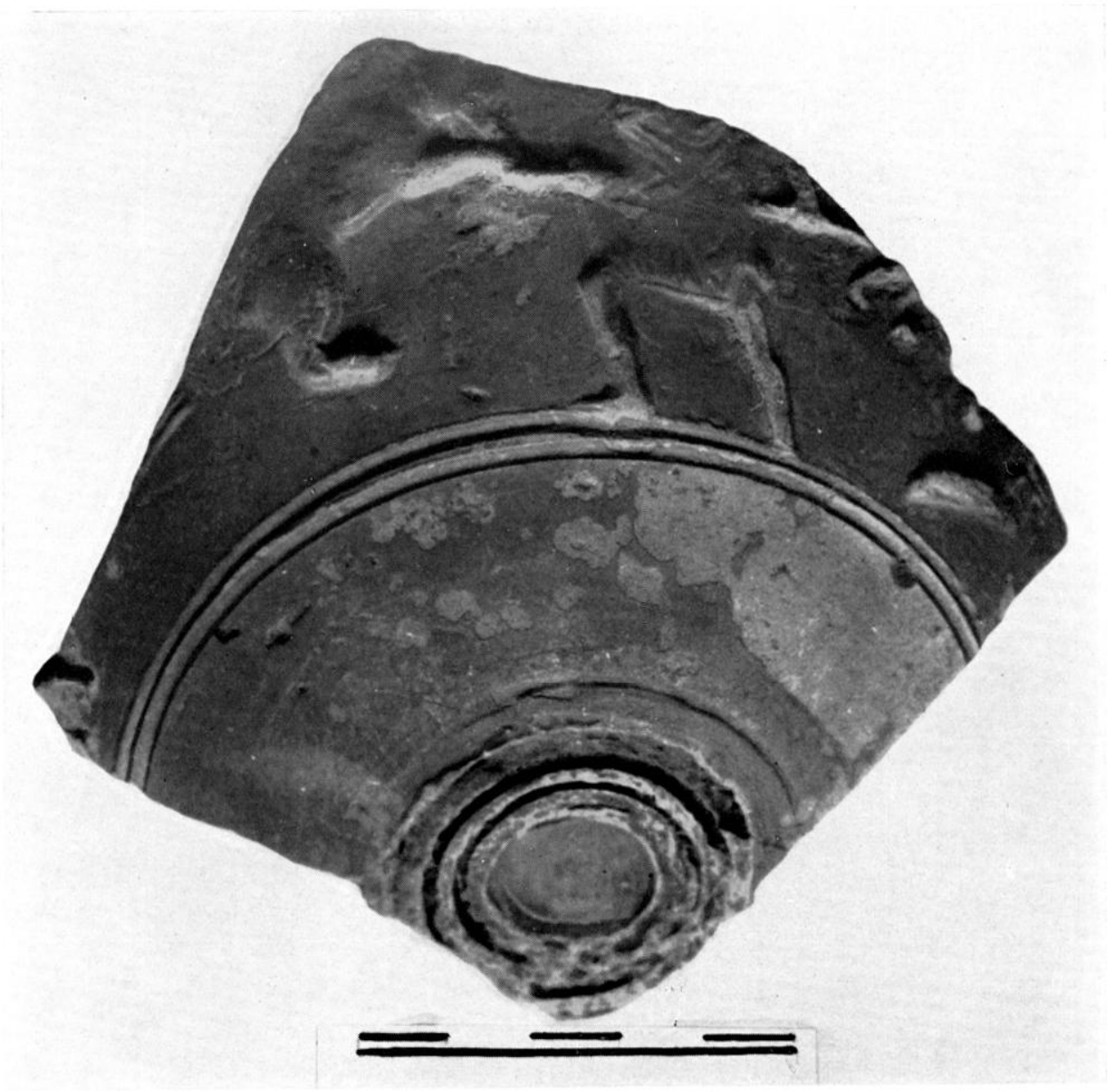

Fig. :20. -.. Vase $1^{\circ} 6$, sirie 6. De gauche à droite : ours, chasseur ; derriere lui, en bas les pattes d'un grand fauve, au dessus, celles d'un animal plus petit.

fond el la couleur originale apparait un peu sur les parties lés plus hautes du décor (zones E 26-F 28). Le pied était collé sur des rainures tracées pour assurer une meilleure adhésion.

Il ne reste qu'une partie du bas de la panse. qui représente une scéne de chasse dans le mème style que le vase précédent. On pourrait se demander si l'on a affaire a des épreuves de moules distincts ou bien à deux rases sortis du mème creux et cassés de façon dillérente. Le chasseur, vètu d'une lunique courte, est dans la mème altitude que celui du no ${ }^{0}$ ), mais inversé. Il est tourné vers la gauche et affronte avec un épieu un ours dressé contre lui. placé au-dessus du sol comme s'il bondissait. C'est plutôt une maladresse du potier. On remarquera que sur ces vases le sol n'est pas figuré ni suggéré. L'ours est très probablement du mème poinçon-matrice que celui du $\mathrm{n}^{0}$ ग.
Les palles de deux autres animaux sont visibles derriere le chasseur: un petit, marchant vers la droite, et un grand fauve probablement, vers la qauche. L'imitation des vases sigillés ilaliques dans le thème. le style el, d'un autre còlé, la disposition des personnages plus maladroite et le dessin plus sommaire des figures sont les mèmes que sur le $n^{0}$ j. Nous n'arons pas eu sous les yeux de vases arétins qui présentent un chasseur vètu, non d'une draperie mouillée el transparente comme sur le vase de M.Perennins, mais d'une tunique courte à plis raides, en V, comme ici. Il en existail sûrement. Lin efiet, le Musée d'Arezzo présente dans ses vitrines un beau poinçon-matrice de ce type, provenant des officines locales. Nous avons pu le photographier grâce à l'amabilité de Monsieur le Surintendant de la Toscane el le reproduire avec la permission du professeur 


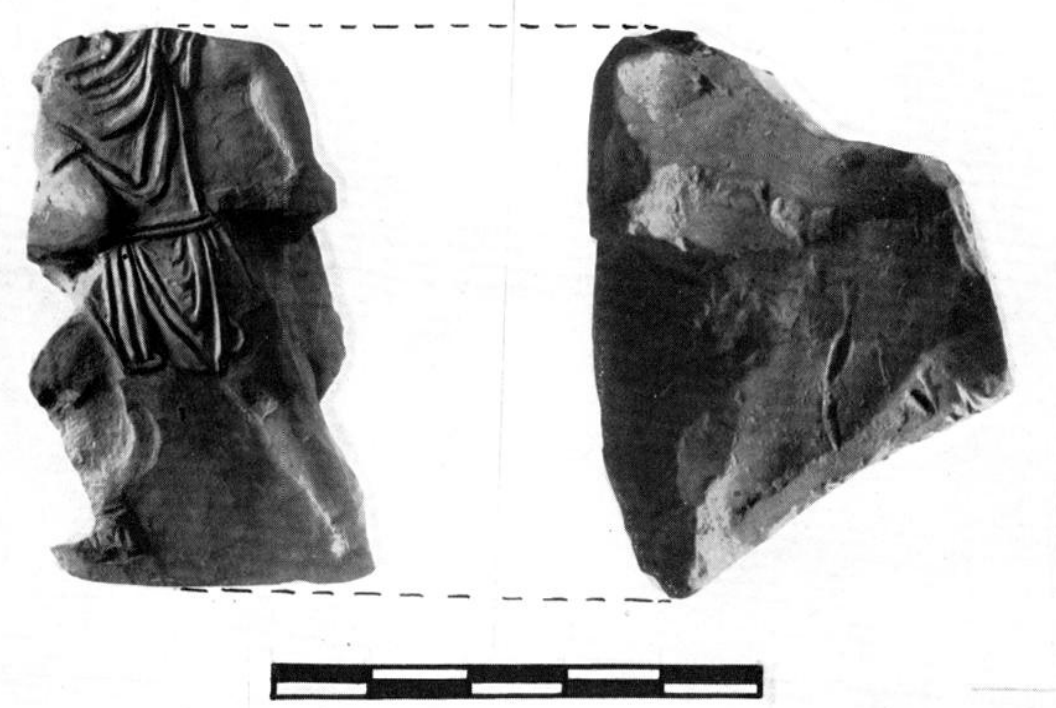

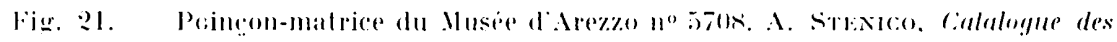
puins'ms-malriess arelins. pl. $8 . n^{\circ} 17$ a. Hant du relief: du talon droit an coude

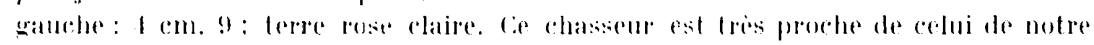

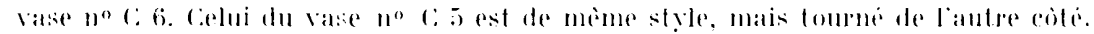

(l'hertor, Herlel)

1. steniro, qui est sur te point de publier un répertoire des poinçons-matrices arétins. Aussi les remercions-nous ici. Comme on peut le voir sur la photographie (fig. 21). l'altitude du personnage est la mème que sur le vase de Roanne : la jambe qauche lléchie. la jambe droite tendue, le corps penché en avant, l'épieu passant derrière le corps, la tunique serrée par une ceinture. Sur le torse descend une série de plis arrondis d'abord, puis en $Y$ ensuite. En dessous de la taille, on voil des plis droils, une série en $V$, el l'étolle soulevée sur chaque cuisse.

Le relief gallo-romain présente les mèmes dessins, mais tries eflacés et dans un formal. réduit. On est amené à conclure que cette mauvaise qualité et celte réduction sont la preuve de surmoulages successifs. Ln effet ce poinçon-matrice, ou un semblable, a servi au potier italique à faire un moule, d'où est sorti un vase; ce vase, vendu en (iaule, a ru son relief moulé avec de l'argile par le potier arverne. De ce creux, l'artisan a sorti un poingonmatrice. Avec cet outil. il a décoré un moule. el de ce moule esl né le vase que nous avons sous les yeux. Nous avons done six passages successifs du molif sur l'argile, avec, chaque fois, une perte sensible de dimensions et de nelleté. Ainsi peuvent s'expliquer la platitude du relief de ces vases par rapport aux figures arétines. de mìme que la perte des détails el la réduction des personnages. que nous avons aussi remarquées sur le vase $n^{0} \mathrm{C} 2$.

()n peut utiliser celle constatation de surmoulage comme critire chronologique, et conclure que les vases arvernes ont été fabriqués peu aprés les vases arélins. Én effet la production des vases 11 avernes semble correspondre à une réaction de défense des potiers indigènes contre l'invasion d'un marché menacé par les produils étrangers, et à une demande de la clientiele pendant un temps restreint. Les vases a grands personnages n'ont pas eu, au $\mathrm{I}^{\mathrm{er}}$ siecle, une grande vogue en Gaule. Les vases Iragendorff 29, carénés, qui gagnent la faveur du public dis avant le milieu du I $^{\text {er }}$ siecle, dis le règne de Claude. abandonnent ces thèmes et préfêrent les décors végétaux, comme les rare: vases 11 fabriqués a La (iraufesenque. Ce n'est qu'i la fin du siècle que les personnages et les animaux redeviendront en faveur. ef dans un slyle tris différent. 


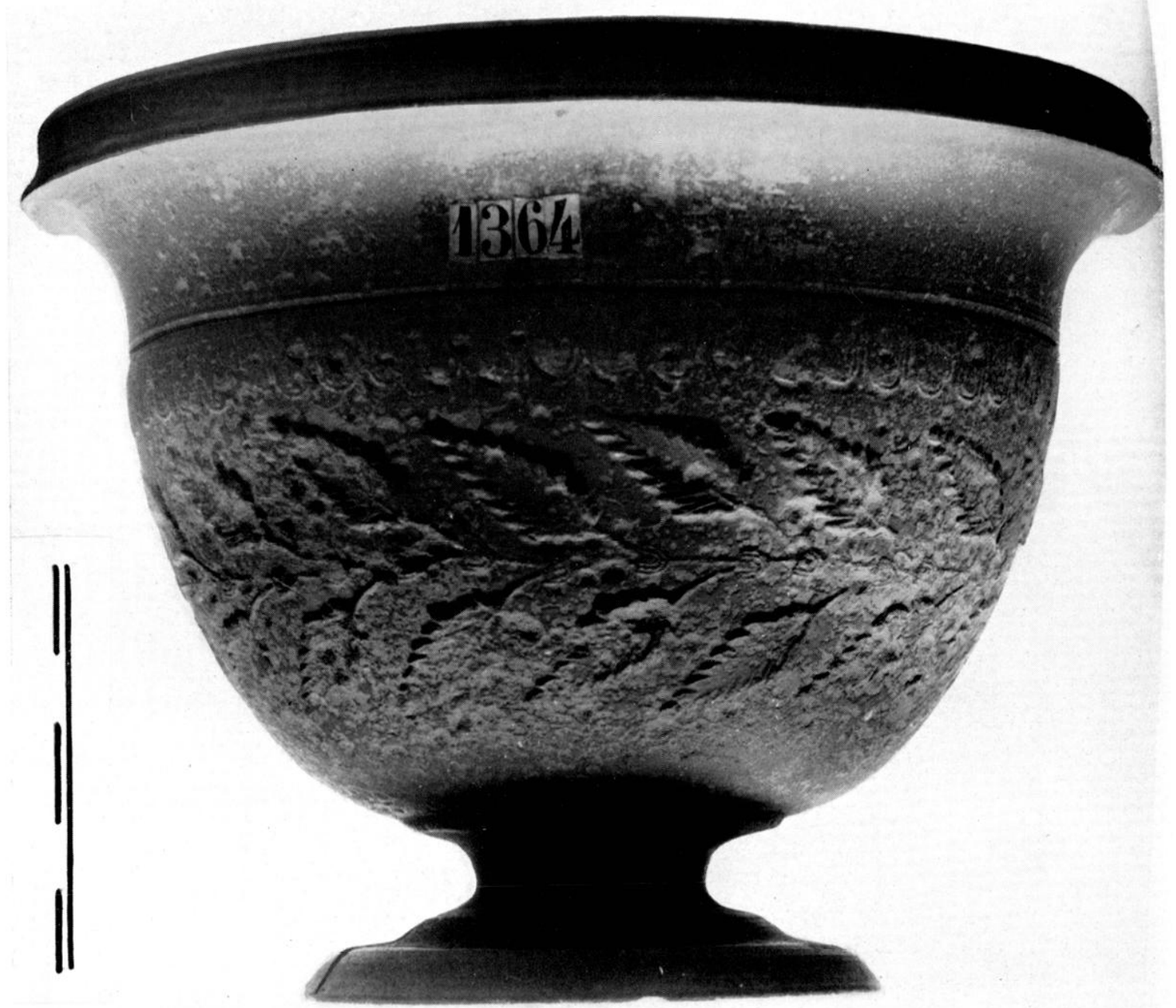

lïg. :2.. -.. Vase $n^{\circ} 7$, série $(:$

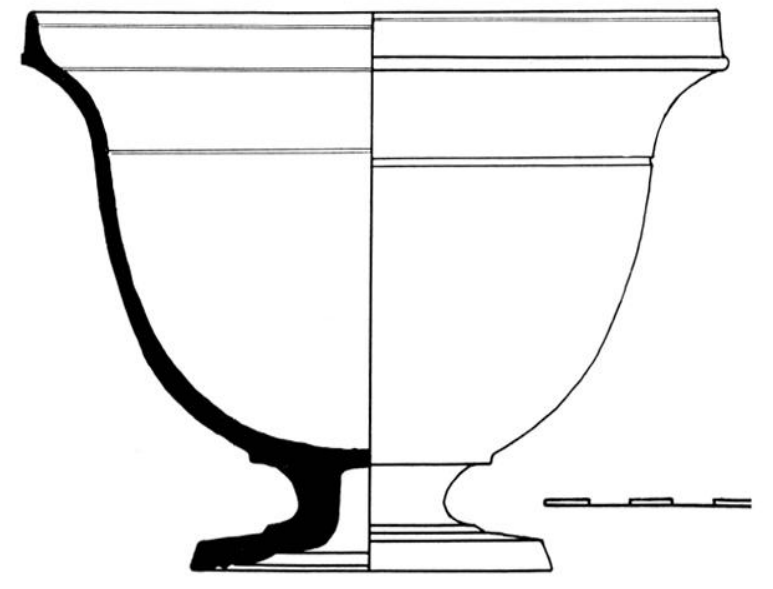

Fig. 23. - Profil du vase $n^{\circ} 7$, série $C$. уo 7 (fix. 22 et 23). -... Provenance: Roanne, rue Saint-Jean, maison Contarel; don de M. Femelat. Musee de Roamne, no 13364. - Bibliographie: néant.

Terre grisaltre surface : exlérieure $\mathrm{F} 26$; intericure : F 24 . Dimensions: hauteur, $12 \mathrm{~cm} .2$; plus grand diamelre, $16 \mathrm{~cm} .5)$

Vase loul a fait remarquable par sa conservation et son décor, bien que le vernis ail été très abîmé. I a décoration est composée d'oves larges, simples, a pendentifs non renflés, et, au-dessous, d'une couronne de feuilles allongées dont les pétioles sont reliés à une lige unique et rectiligne par un ornement au dessin minutieux, en forme d'ove minuscule. 
Ce vase est attribuable aux oflicines de I eroux pour plusieurs raisons. I a lerre et lo vernis sont semblables a ceux des produits précoces déja etudies. De plus. la collection Plicpue-Dalhomniere, de I ezoux, conserve les fragments d'un calice dont le décor est semblable. Autour de la panse, on voit le mòme bandeau de feuilles allongées, avec les mèmes ores minuscules a la base des pétioles, la mòme terre grisatre avec vernis rouge mat dont il ne reste que de faibles traces. Ies pélioles sont peut-ètre un peu plus souples que ceux du vase de Roanne, mais tres peu. Au-dessus. courait une ligne de feuilles slylisées placées rote a rote verticalement; elle n'est pas complite, ear le haut du vase manque. Itme Mathonniere a trouve celle coupe tris probablement en compagnic d'une Iress belle série de vases 29 archaïques, dans les fouilles qu'elle a pratiquées dans un terrain allenant a sa maison, a Lezoux ${ }^{36}$ bis. In autre fragment de forme 11, du mème polier, est conservé au Musée des Intiquilés nationales. Il provient des fouilles du I)r Plicque, à Lezoux, dont le produit a élé acheté par le Musée, au débul de re sierle. Les feuilles sont les mèmes que celles des deux coupes dont nous venons de parler. el, en outre, les oves sont identiques à celle du vase de loanne. Sur ce tesson, les feuilles sont placées au bout de tiges qui s’épanouissent comme celles d'une plante et se réunissent sans ornement (fig. 24).

Cetle coupe est peut-être la plus incontestablement proche du style ilalique de toute la série éludiée, par l'élégance de sa forme. les éléments et l'ordonnance de son décor. On pourrait penser au premier abord que la rigidité de la tioge centrale est une caractéristique maladroite du style indigene. II n'en est rien. Le professeur stenico vient de publier des moules du potier Rasinius, d'Arezzo, qui présentent exactement le mòme anneau filiforme et rigide, sur lequel sont accrochés des pampres ou des feuilles d'olivier ${ }^{3 i}$. Ce n'est pas le seul décorateur à avoir utilisé ce motif :

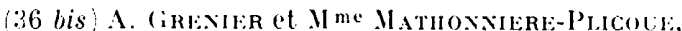
dans Gallia. XIX 1961.

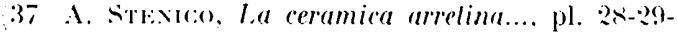
$3 C-31$.

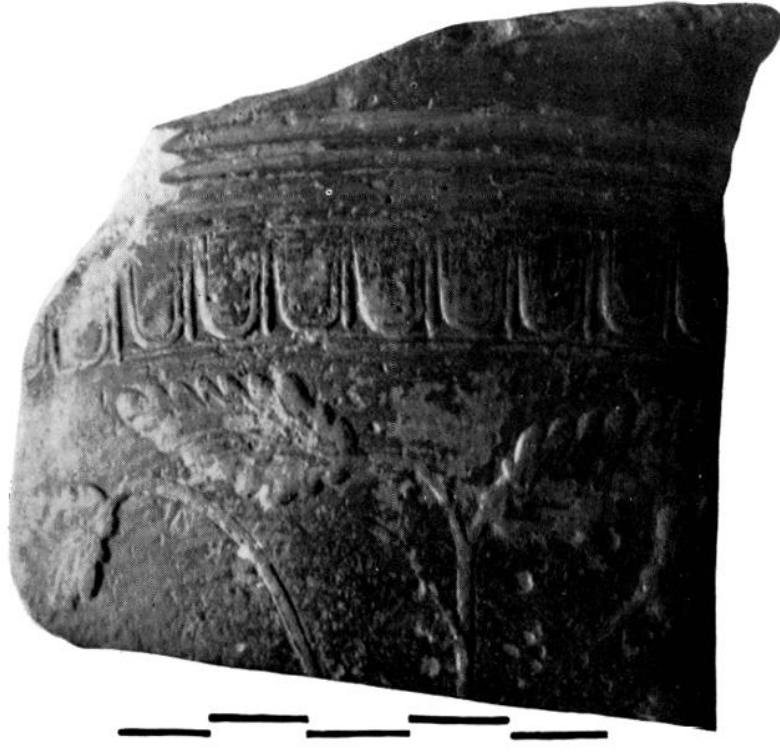

Figr. 24. -- Fragment de vase Dragendorff 11, conservi au Musce des Antiquités nationales.

on le retrouve. par exemple. sur un autre fragment, peut-etre de Comelius ${ }^{38}$. el sur une petile coupe a bords droits ${ }^{39}$. Sur ces tessons, les feuilles en losanges sont tris proches de celles de Roanne. Ces décors sont Iriss souvent. accompagnés d'une rangrée ou deux d'ornements stylisés, feuilles, coours... (fig. 25)), juxlaposés étroitement. sur un des moules donnes par le professeur stenico, e'est une fleurelte à huil pétales - tris proche de celle de nolre vase no $3 \ldots$ qui est utilisée. Au-rlessous de retle frise, le potier en a placé une autre d'ornements triangulaires en forme de fourreaux de poignards ou de torches. donl les manches ou les flammes monlent dans l'intervalle des fleurs. Ces bandeaux sont interessants a plusieurs titres. sur le vase trouvé par Mme Mathonniere. on voit une frise de celte sorte au-dessus de la couronne de feuillaget. On la voit aussi, tracée en ornements ruciformes, sur notre vase $n^{0}$ 1. ce qui peut latsiser supposer que les deux vases sont d'un mème potier. Deuxiomement, ce double décor est d'un type qui pourrail aroir inspiré notre vase $n^{0} 4$. Ia petite ove qui se troure a

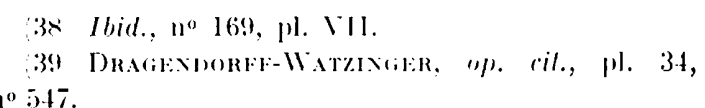




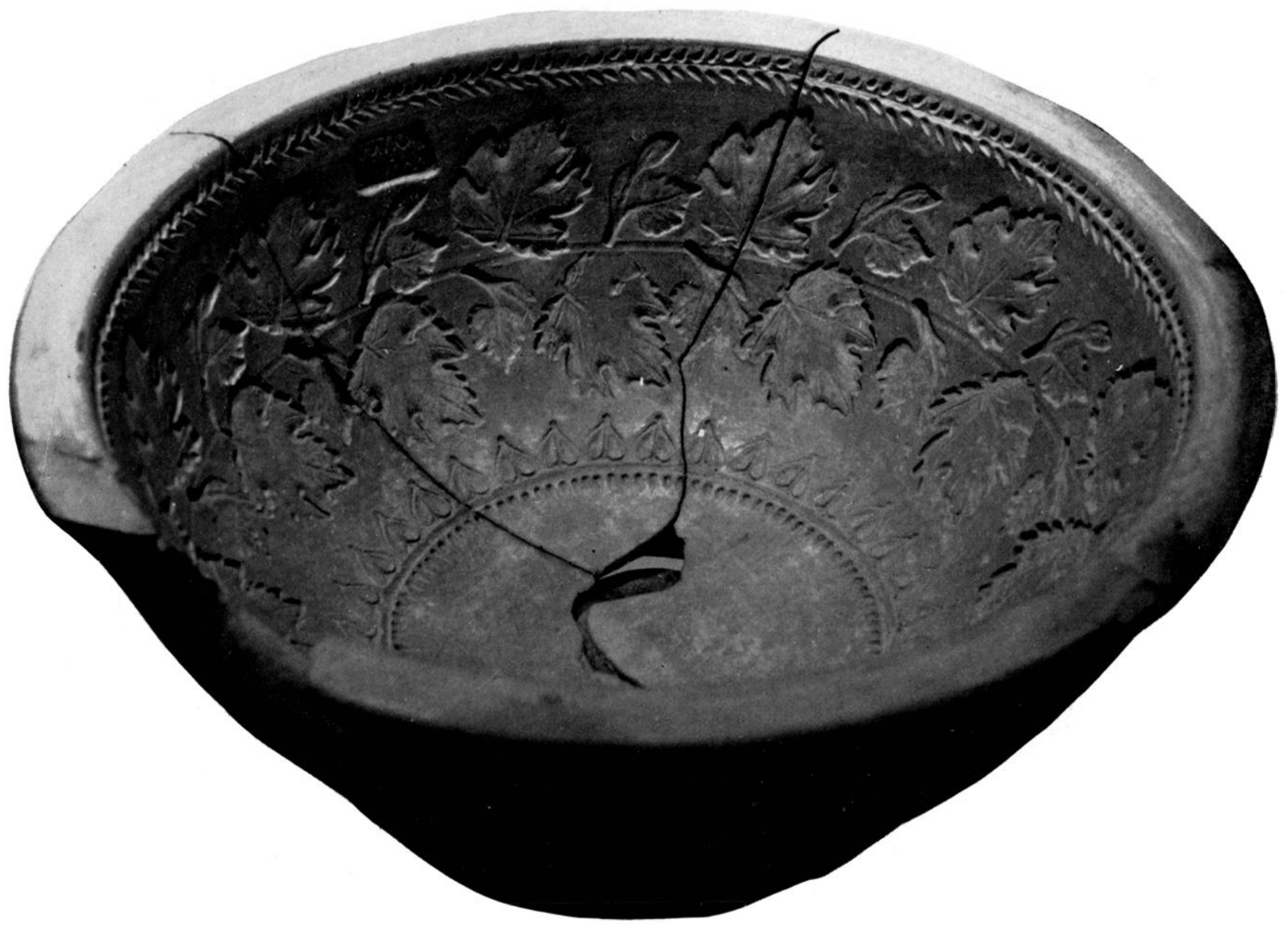

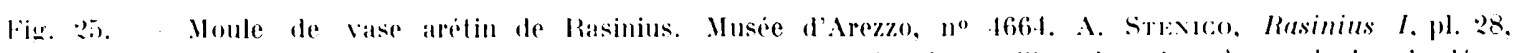

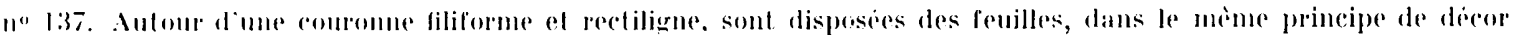

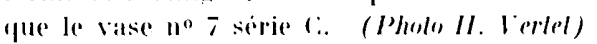

l'allache des péfioles a son correspondant aussi sur les réramiquess arétines. Nous en avons vu de meme dimension a Irezzo mème. sur un tesson trouve recemment a Mlesia (Ies I aumes) par .I. l'ahbé Jovignot, directeur des foulles. nous avons releve une frise d'ores identiques a celles de Roanne, de môme dessin of de memes dimensioms. Malleureusement. le moreatu est tres petit al ne porte, pour lout. relief. que trois oves. Il faisail probablement partir d'un gobelel. Sa surface est rouge ef son vernis peu brillant mais solide. Il ne parail pas arélin. Les grandes oves qui enlourent la coupe se retrouvent sur les vases arélins. avec un dessin analogue. Sous pourons done conslater que tous les éléments de ce vase sont inspirés directement par l'art d'Italie. al précisément par celui de l'époque augus- lénne. Ce document pose nellement le problime de la présence a lezoux d'ouvriers venus des aleliers italiens, que re solent des hommes de la Péninsule ou dese Ciaulois qui aicul fail le vovage pour apprendre les procédes de la lerre sigillore.

Vous verrons dans la conclusion de celle elude qu'un des potiers lédosiens. Hepomarus. a tres solurent orne ses vases de rourommes de feuillages reunies par un fil rigide a a min les. protioles des fenilles aved des ormements géomélriques. On peut se demander s'il n'est pas l'auleur de ce vase. bien que l'on n'ail. pas encore trouvé sur ses oruves la petile ove; ou si ce n'esl poinl quelqu'un qui le louchail de pres, un de ses compangnons. ot peul-êlre son maîl re. 


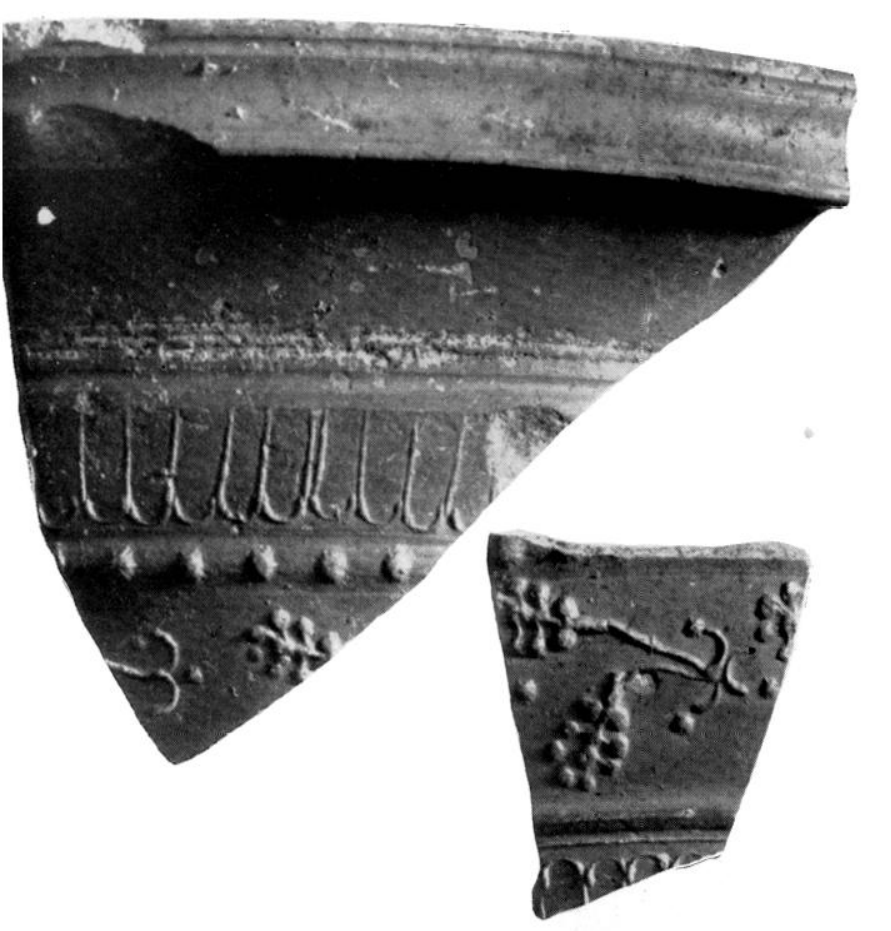

à des demi-cercles imprimés. Iu-dessous. sur une moulure, une ligne de points espacés. que II. Périchon a reconnu itre des fleuretles minuscules. La frise présente des élements végélaux, peut-ille des liges de graminés. Elle a été imprimée avec deux poinconsmatrices. L'un représente huil points réunis

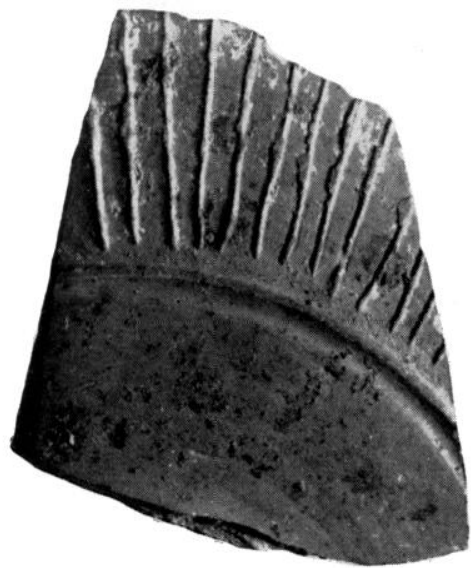

Fig. 26 . Vase $n^{\circ} x$, sirie 6 . L.es fragments ne peuvent itre recolles; mais ils permettent de reconstituer le decor.

$$
1: 1
$$

No8 (fig. 26 et 27). - Prorenance : inconnue. Musée de Roanne, no 000 ). - Bibliographie: néanl.

I a terre est la mème que celle des nos 2 el 7 ; la surface est rouge vif. par endroit proche de F 18, d'une teinle absolument inhabiluelle sur la céramique siqillée italique et gallo-romaine.

Trois fragments permettent de reconstituer un décor tris curieux. En haut se trouvent. non des oves classiques, mais des lignes verticales raccordées plus ou moins exactement

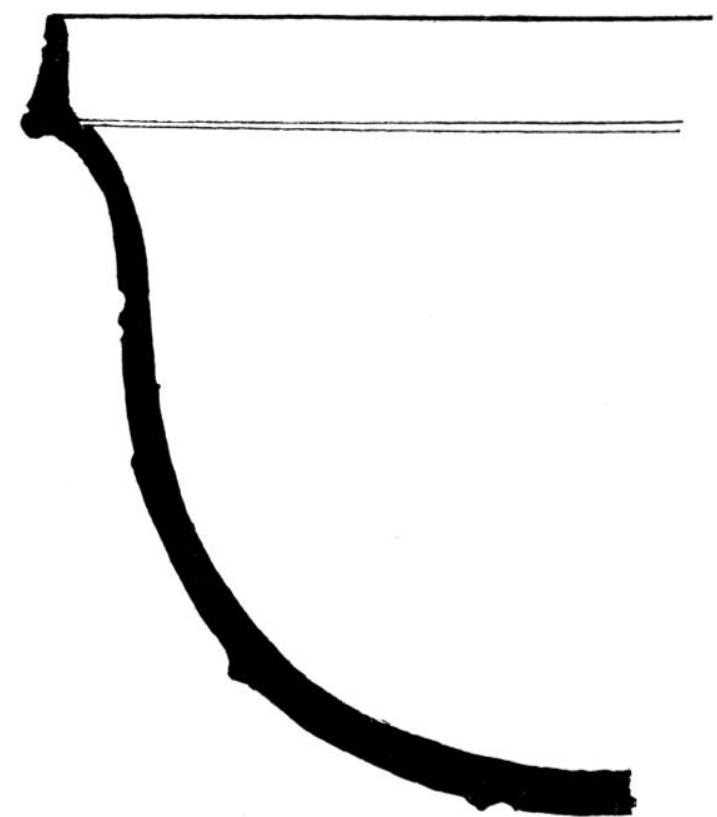

Fig.. $: 7 . \quad$ Profil reconstitué du rase $n^{\circ} \&$, sirle $r$

à une tige centrale, l'autre. le mème demi. cercle qui ferme la base des oves et le haut des godrons de la panse. Des lignes Iraceess aver une pointe réunissent ces impressions. Il n'est pas sùr que les trails verlicaux des oves et des godrons aient élé imprimés ; leur irrégularitó peut laisser supposer qu'ils ont éé dessinés a main levée.

Plusieurs éléments de ce décor évoquent l'arl arélin : la panse ornée de godrons el la frise de feuillagest. la ligne de gros points espacés qui se trouve souvent au-dessous des oves. Mais ce document cst surtoul intéressant. par la façon dont l'artisan indigrene a rendu ce qui était sous ses yeux. Les oves allongées arétines et les godrons ont été reliés à un motif bien connu de l'art local : les demi-cercles juxtaposés en guirlandes ou en arceaux ${ }^{40}$.

40 Ainsi certaines (moveses de Bargalhes: Dr.aki-

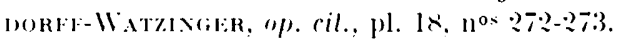

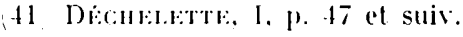


Nous n'avions point encore vu sur les productions lédosiennes précoces des oves de cette sorte. Nous les rapprocherions plutot d'autres ropiess maladroites qui existent sur des vases en terre blanche de la région de saint-Rémyen-Rollat, Gannat. Vichy. Yous avons là un décor contemporain des premières formes carénées décorées a relief. ou même antérieur it elles. Ce calice est le témoin que certains vases 11 ont été copiés par des potiers indigènes sur des originaux de style italique. et non ronçus par des poliers venus d'Italie en (iaule.

Iese lieux de fabrication des rases 11 de Roanne sonl donc bien délerminés par les eludes anciennes. et les rapprochements que nous avons pu faire.

La dale des documents italiques (série $\mathrm{A}$ ) est donnée par les éludes déja publiées. Nous arons été amenés a vieillir le vase de Volus (série B et il le placer sous le rìne de Claude. Pour les vases de Lezoux (série C), nous n'avons pu faire de comparaisons avec d'autres vases dalés. car un seul vase 11 arverne a élé publié juscqu'i présent et il est d'un style différent. de ceux de Roanne ${ }^{42}$. Jussi avons-nous été amenés, pour siluer celle série dans le temps, a reposer le problème des fabriations précocess de Lezoux, au moyen des doruments récemment publiés el des inédits que nous avons trouvés dans diverses collections of musées.

\section{La chromologie de la sigillée de Lezontx aue débul du Ier siècle}

De Trajan a Hadrien el mème plus lard. la chronologie des ateliers de Lezoux est bien ronnue par plusieurs études, quoiqu'il reste rncore beaucoup de problemes à éclairer. Wais nous avons bien moins de I ravaux sur ce yui se passail au fer siccle et surtout dans les premieres decennies. La production est. mal connue. asser peu abondante et on a peu de trouvailles dans les sites datés. Nous allons donc préciser à quelles conclusions sont parvenues les recherches modernes, ansez dispersées. puis exposer les comparaisons qui

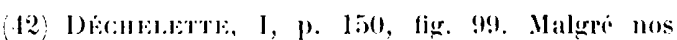
recherches et celles de nos amis, nous narous pu savoir encore ce qu'est devenu ce vase. nous paraissent permeltre de nouvelles hypothises.

Les études sur le début de la fabricalion de la sigillée a Lezoux sont restées longtemps fondées sur la seule production locale précoce que l'on connaissail avec certilude : celle des vases 29. En comparant certains d'entre eux avec les séries bien datées provenant de La (iraufesenque (Tarn), chez les Rulhènes. on les avail places sous le régne de Claude. Comme c'élaient les premieres productions connues de Lezoux et qu'elles avaienl plusieurs points communs aver celles de la vallée du Tarn, on avait silué à celle date le commencement de la fabrication des vases moulés lédosiens; on avait conclu de là aussi que les fabriques ruthènes, adonnées à la production de la sigillée depuis longtemps déjì. avaienl eu une influence directe, soil parce qu'elles avaient envoyé des ouvriers spécialisés. soil paree que les produits arvernes avaient copié leurs formes el leurs décors ${ }^{43}$. Celte conclusion. salisfaisante dans l'ensemble, ne donnait cependanl pas la solution de tous les problemes. notamment celui du style décoratif tres original d'un polier arverne. nommé Hepomarus. tout différent de celui qu'ulilisaient les arlisans du sud de la (iaule, surtout beaucoup plus proche des produits de l'art augustéen. On admellail volontiers que les Ruthenes n'avaient pas fondé les fabriques lédosiennes et qu'elles existaient depuis longtemps auparavant, mais on pensait qu'elles ne mellaient sur le marché que des vases peints de tradition indigene et de la vaisselle commune.

Récemment. deux archéologrues ont attiré l'allention sur des vases sigilles sans décor. fabriqués à Lezoux, et dont les formes el less estampilles sont étonnamment prochess dre celles d'Ilalie du lemps de Claude. de Tibire. ou mème d'Auguste. H. Comforl a publiét4 des estampilles de forme I ypiquement arétines conservées aux musces de lemoux el de Clermont-Ferrand. Celles qui paraissent les plus anciennes avaient été imprimées sur des

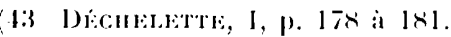

(14) H. Comsont, in arreline-lype signalnue from

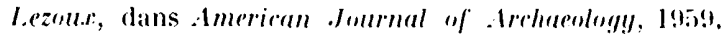
p. $179-180$. 
coupelles de forme Italtern 8 ou Ritlerling a el donnaient RVTEI sur une ligne inférieure et une palme couchée sur la ligne supérieure. "si la premiere moitié de l'estampille avail été cassée el avait disparu, écrit l'auteur, on l'aurait remplacée de confiance par "cn. aTEI ", - c'est-à-dire par l'estampille d'un potier arétin très connu, qui a travaillé sous Auguste, et dont les produits ont été trés souvent trouvés dans les provinces de l'Empire. On a donc là une imitation lrès exacte de la vaisselle italique.

Nous ajouterons a cet argument sur la fabrication précoce de vaisselle sigillée a Icezoux, la lecture d'une autre estampille signalée par l'auteur dans le même arlicle. Elle se présente ainsi : RUTEN/FEC. A. sur deux lignes. Il nous semble possible de restiluer : Rulenus fecit arrelinum. En effet, on connail une autre marque de potier. trouvée à Vindonissa, rédigée : SCOTIVs FE ARETINV. Mme Ettlingrer, qui a signalé ce remarquable document et l'a savamment publié et daté de 20 après J.-C., le lit : Scolius fecit arretinum; elle traduit arretinum par vase arétin ${ }^{45}$. Cetle opinion a été confirmée par un article de Frantisek Krísek, qui a rassemblé les textes anliques oì est employée l'expression arretina l'asa. pour désigner les produits des oflicines d'Arezzo ${ }^{46}$. Il est maintenant certain que l'adjeclif neulre a élé substantivé pour désigner le vase a vernis rouge tel que les ateliers arétins en avaient répandu une si grande quantilé dans tout le monde antique. Les estampilles porlant ce mot sont tres rares en Gaule el tres précoces. Il est vraisemblable qu'une fois la production gallo-romaine bien établie, les potiers n'ont point attaché lant d'importance a faire passer leur production pour une vraic marchandise d'Italie ; on peut supposer aussi que le mot est devenu moins courant, avec l'aflaiblissement des fabriques arétines.

(45) E. ETruxake, Ein Sigillala-1)epolfund aus dem Legionslager Vindonissa, dans Cermania, 33, 1955, 1, p. $369-371$.

16 Fr. Kǹiz̀n. Iasa arrelina, Rei cirelariue Faulorum Acla III, 1961, p. 35-43.
J. Gourvest ${ }^{47}$, de son rólé, a étudié une assielle estampillée du potier Atepomarus, bien connu pour avoir travaillé a lezoux. Son profil est proche de celui des vaisselles il aliques. Elle appartient i la forme I)ragendorfl $17 \mathrm{~A}$. avec paroi verticale fortement moulurée. encore appelée Ioeschke 2 A. C'est une forme assez rare en sigillée gauloise, mais fréquente che les potiers augustéens arétins ou ilaliques. I.'exemplaire le plus proche qu'ail relevé l'auteur est signé de Xanthus, de l'alelier de Aleius (Arezzo).

Les estampilles et l'assielle signalées par II. Comfort et J. Gourvest ne sont que le début d'une étude sur la sigillée lisse des fabriques arvernes. qui est indispensable. el qui est appelée a s'étofter rapidement dans les années a venir. En effel, les fouilles de Lezoux. qui reprennent, en fourniront rertainement des échantillons, si ce n'est plus. I e relevé complet des collections particulières et des musées révèle déjà des assiettes anciennement découvertes et inédites. Ainsi la collection Mathonniere en contient de belles séries trouvées sur place. Nous présentons ici (fig. 28-29) quelques documents inédits, qui montrent que cette recherche est fruclueuse : le no 1 est une assiette signée $\mathrm{ATEPOF}$, de la collection Fabre, dont nous préparons la publication complète. Elle est proche de celle que J. Gourvest a relevée ì Châleauroux. Le no 2 est également une assiette et la collection Fabre la contient en quatre exemplaires qui sont estampillés de trois abréviations inédiles ef encore énimmatiques. Les lettres sont belles el bien tracées, et la disposition est sur deux lignes, a la mode italique. Ie profil est proche de celui d'Atepomarus. le pied moins haut et le fond plus bombé. Cess documents proviennent de fouilles failes a Lezoux. Le no 3 porle un nom de consonance gauloise : CATICORIX, que ne mentionnent ni Déchelette, ni Oswald. Il provient probablement de fouilles faites a Roanne. car il esl déposé au musée de cette ville. S'il provenail de la collection Déchelette, c'est-a-dire d'achats faits a Lezoux, il serait mentionné dans les

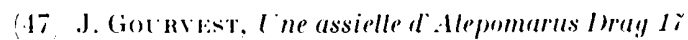
1. dans Rei Crelariae Fatulorum Acla $I I I, 1961$, p. 19-21. 

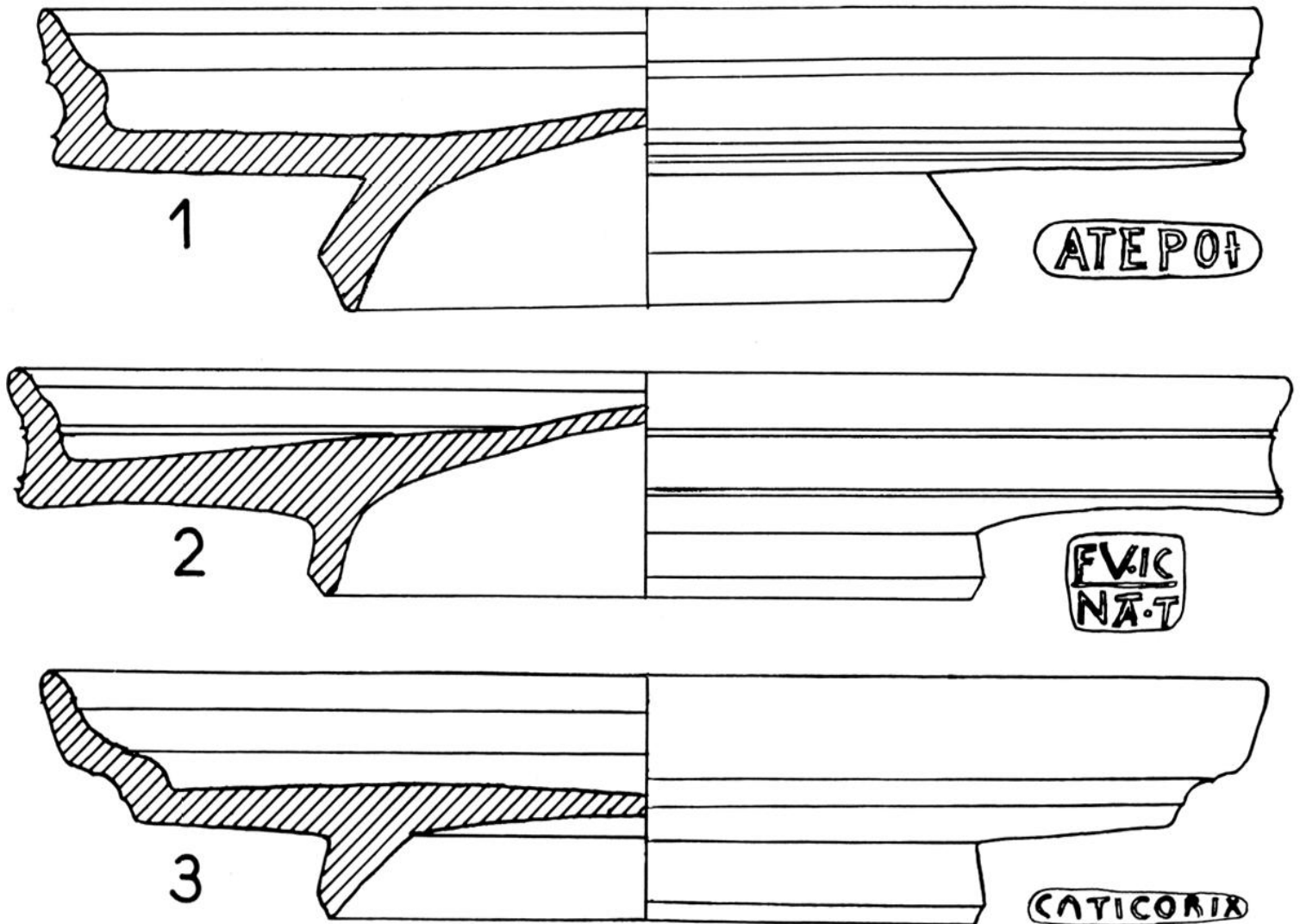

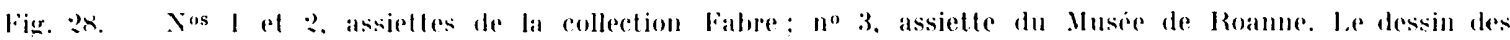
r:stampilles est tres agrandi : voir figr. "?!. .

Vases ornes de la Gaule romaine, semble-t-il. son profil nous parail proche de celui d'une assielle trouvée a Impurias ${ }^{48}$ el estampillée OF I.ABIO. potier de La Graufesenque. qui a travaillé à l'époque de Claude (37-54). Son vernis rouge monlre que des aleliers arvernes avaient bien assimilé, a ce moment les procédés de fabricalion italiques. Par ailleurs. (Oswald avail dejà signale dans son Inder une coupelle. forme Ritlerling 8 . i Cirencester. signer

\section{ATEPOB 2 ENATICONID}

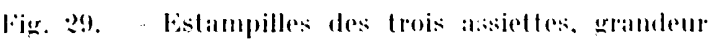
niaturere.

(t) II. Alsunaro, Las necropolis de Ampurias, 11. incineracion Patel $n^{\circ} 12$, p. 2.10 et Tablas tipologicas... terra sigrillata, epoca de Claudio.
ITIPOMAR, une autre de mème forme ¿ Poitiers signée $\operatorname{TTEPO}$ MN, une autre encore de forme Rillerling 9 a Amiens. signée ATEP(). L'auteur date lous res vases de l'époque de Claudes9.

Il est done cerlain qu'il exista à Lezoux. des la fin du regne d'Auguste, des 10 environ. pense II. Comfort, une fabrication de vaisselle imilé lros fidibment des probol ypes il aliques. Ce savant, qui prépare un corpus des estampilles arélines. avertit mème les archécologuess dans son arlicle. que ces produits sont parfois si bien imilés qu'il faudra se méfier des confusions. si l'on a a faire non à des formes entières. mais a de petits fragments. Il serail tres important, pour l'hisloire des fabriques de lacoux, de savoir comment a evolue celle

(49) F. Oswato, Inde. of Pollers' Slamps on Terra Sigillala, 1931. "Atepomarus ". 
fabricalion. Elle ne ful pas un phénomene exceptionnel el pasisager. puisque nous avons d'une part des doruments de la fin du rigne d'Auguste ou du début de celui de Tibere. et d'autre parl un proupe de documents claudiens, comme nous venons de le voir. Devant ces produits très précoces des fabriques de Lezoux, les archéologues abandonnèrent donc la posilion de Déchelelle el reculerent au débul du siecle le commencement de la fabrication de la terre sigillée lisse. Mais ils ne connaissaient pas de produits moulés aussi anciens. Aussi, sur ce point, en resterent-ils aux conclusions antérieures : Lezoux avail commencé en 40 apris J.-C. a fabriquer des vases a reliefs. el cela, sous l'influence de Ia Ciraufesenque. L'ensemble des vases 11 de loanne (série C) nous incile à modifier cetle opinion et a reporter au début du sierle le moment où s'installa, dans les ateliers arvernes. la fabrication en série des vases moules de lechnique italique. Nous allons voir que plusieurs faits confirment celle nouvelle datalion.

le site oì a élé lrouvée une partie importante des vases de Roanne est un cimetière, dont la période d'utilisation la plus importante est l'époque d'Auguste. Quelques éléments sont plus tardifs, notamment, le vase du potier Volus de La Graufesenque, que nous avons silué dans "la période de splendeur" des officines rulhines. moment où ces fabriques avaient envahi les marchés, mème au centre de la Caule (Claude-Xéron). Or, le slyle de la série des vases arvernes décrits plus haut est bien différent. On se rappellera que deux d'entre eux - - les seuls publiés -- ont été pris pour des produits des centres arélins; nous avons vu que deux autres sont proches des aures de Marcus Perennius, el que le no 7 est une copie encore plus fidèle des produits italiques. Les autres montrent des mélanges variables d'influences étrangères et locales, dans un style très hésitant encore. En conséquence. il n'est pas possible de nous en tenir aux conclusions anciennes, nous semble-t-il el de dater de 40 ap. J.-C. des vases si proches de prototypes augustéens trouvés en assez grand nombre dans un contexte en géneral plus ancien que rette dale.
L'élude des autres vases moulés de Lezoux. de forme 29, nous amine a une conclusion identique. Dans l'ensemble des bols raréné: de Iezoux, on a été conduit. depuis les éludes de Déchelelte a distinguer plusieurs périodes ${ }^{50}$. Lne catégorie de ces vases. notammenl ceux de Petrecus. par exemple, sont proches par leur style des produits de La Graufesenque, el en ont vraisemblablement subi l'influence, comme l'avait écrit le savant roannais. On peut les dater effectivement de 40 ap. J.-C. ou plus Lard. Mais d'autres sont très diflérents du bol 29 rulhene classique de la période de splendeur (40-60), dont les caractérisliques ont été bien définies. Sur ces roupes archaïques, la levere, au lieu d'otre évasée comme celle des vases de la période de splendeur, el comme on la voit rhe\% Petrecus, est rompose seulement d'une étroite moulure verticale. Nous avons lit un critere que l'on ne retrouve. a La (iraufesenque. que sur les loules premieres productions sigillées \$1 (période libérienne). L'influence des oflicines du sud de la Gaule sur celles de Lezoux à l'époque libérienne serait peu probable en elle-même, en raison du peu de rayonnement de celte fabrique qui débutait alors. Ies ressemblances que nous avons relevées entre les productions précoces des deux centres s'arrètent lia, et nous pensons qu'elles doivent provenir d'un protolype commun.

Dès le départ de la fabrication. les caracléristiques mèmes qui servirent plus lard a rapprocher les deux capitales de la céramique gallo-romaine les différencient. Par exemple, les lignes pointillées qui encadrent la moulure tracée entre la panse el la frise manquent à Lezoux, ou sont extremement fines et denses. A I a Graufesenque au contraire, on considere la forte taille des points comme un indice de la période précoce. I e diamétre de cet ornement grossira dans la première fabrique et diminuera dans la deuxieme, pour se standardiser vers

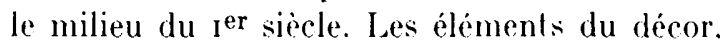

(5) F. (Oswan), Carinated Bouls (form 29) from J.ezond, dans .Journal of Roman Sludies, 27, 19:37, p. 210-214. J. Mantr, Lévolution des rases sigilles ornes de l.ezoutr. dans Bullelin hislorique ol scientifique de litulergne, I.XII, 19.42, 3, p. 185-193.

(5) Hıкмит. l.a Granfesenque. p. 18:2. 
romme son ordonnance, présentent sur les vases 29 de Lezoux des différences tout à fait irappantes avee les produits ruthènes, presque autant qu'avec les produits arvernes plus lardifs. C'est sur ces vases précoces de Lezoux que l'on trouve des oiseaux, des fleurs, des quirlandes, des ensembles, que l'on croirait démarqués des fresques de l'Ara Pacis ou des sculptures contemporaines de ce monument. reliefs inconnus sous celle forme a Ia (iraufesenque. I.es atlaches de pélioles sont. en cette période, particulierement significalives. Elles sont de l rois sorles : une gaine évase en cornet, analogue par exemple à celles des frises de l'Ara l'acis ou de certains plats d'argent du

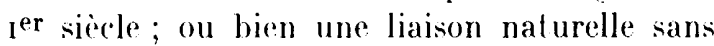
élément accessoire, ou bien, troisiomement, un molif slylisé géomélrique dont Hermel ${ }^{52} \mathrm{ni}$ Oswald ${ }^{53}$ ne présentent aucun exemple pour les productions rulhènes. et qui semble bien raracteristique du Centre de la Gaule. En revanche. dans un inventaire que nous faisons des vases précoces de celle région, nous avons rarement rencontré les épissures enroulées si fréquentes a la Graufesenque. On conclura done que la forme de la live aulant que le décor de ce premier groupe de vases 29 lédosiens presenle lous les caraclieres d'une fabriralion de la période augustéenne ou libérienne. ef aucune lrace de l'influence ruthene.

Plusieurs vases 29 du polier arverne Alepomarus présentent les raractéristiques énumérées ci-dessus. Ainsi, il affectionne les pelits motifs géométriques pour lier ses feuilles entre elles. Il les allache volontiers. comme certains arétins. a une tige rigide. qui enserre le vase d'une ligne circulaire ${ }^{54}$. Bien que l'on n’ait pas encore relevé la petite ove parmi ses molifs d'attarles, il pourrait. lui-meme ou quelqu'un de son alelier. être l'auleur du vase $11\left(n^{\circ} 7\right)$ qui présente ce lype de decor. inconnu dans les publications de Ia Graufesenque ou de Montans. Son style est a ce poinl original que loul ce qui, dans les vases 29 de lezoux, etail nellement dilmérent de l'arl

(52) Ibid., pl. 35) bis.

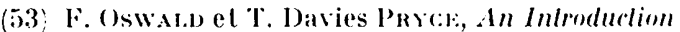
lo the sludy of Terra Sigillata, pl. XX.

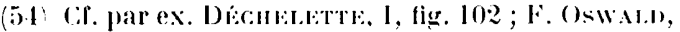

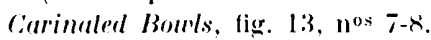

ruthène, avail été appelé "de l'école d'Atepomarus". Pour cela, l'hypothèse qui faisait débuter les vases a reliefs arvernes en 40 apris J.-C. sous l'influence des ateliers du sud se trouve en défaul.

Xous avons vu plus haul que cet habile artisan a lourné des les premieres années de notre ire des assietles de type augusteen ou liberrien. On voil aussi apparaitre d'un seul coup. sur ses vases ornés, l'arl le plus beau qu'on puisse trouver sur les bols moules de Gaule, un des plus proches en même lemps de l'art romain. "Ses poincons-malricess sont d'une délicatesse extreme; ils ont été imprimés aver une habileté et un sens de la mesure surprenants. Quant au relief, tres léger. il ne laisse apparaître aucun des défauls ordinaires du moulage, bavures, impressions trop faibles. trop fortes ou désaxées des poinçons ${ }^{55}$. "Ses coupes sont d'une perfection technique et artistique supérieure a celle de Libertus. lo maître artisan du début du r ${ }^{\mathrm{e}}$ siècle. L'influence de lart augusteen est tres nelte. Cne de ses frises porte des feuillages tres proches de ceux que le potier arélin Xanlhus a placés sur le haut de ses vases ${ }^{56}$. Ene autre ressemble élonnamment au rebord d'un plateau d'argent du trésor d'Iildesheim57, daté du début du $\mathrm{I}^{\mathrm{er}}$ siecle.

Il paraî donc pro vaisemblable qu'un fel potier ait allendu vingt ou trente ans pour produire ces vases moulés. Ses produils, décorés ou non. ont les mèmes modieles, contemporains. Ils étaient fabriqués par les mèmes arlisans dans la Péninsule. avec une pâte ef un vernis identiques. I a diflicullé qu'il pouvait eprouver pour oblenir des décors en reliefs ne lenail pas a la confection du moule ni au démoulage, ni au linissage. bien moins dillicile que le lournage d'une assielle i rebord fincment mouluré ; elle residait dans la fabrication des poingons-matrices el l'ordonnance du

(5) J. MARTIx, op. cil., p. 19:3.

56: Römische Kelehgefässe mil Reliefschmuch gefunden in Mainz, I)ie Altert ïmer unserer heidnischen vorzeit, 1905, pl. 2x et no 5033.

(57) Cf. récemment H, Kïтusx, Beilräge zllr hellenistisch-römischen Torenlili, II, Jahrbuch des. rïmisch-germanische'n Zenlralmusemms .Mains, la:s, il. 16. 
decor. Or Llepomarus n'apparaill pas comme ayant forgé longuement (pendant trenle ans) un art laborieux el tatonnant qui serail enfin parvenu a une grande mailtrise. Par la finesse de son dessin et la sûreté de sa main, tous les bols a reliefs que nous connaissons de lui apparaissent comme ceux d'un homme qui a débuté dans le métier, l'ayant appris aupres d'un polier savant, formé à l'école d'Arezzo. Toules ces raisons, alliées à son indépendance par rapport a l'art ruthene, nous amenent ¿ conclure à une date beaucoup plus précoce pour les premiers vases décorés de ce polier et i les placer, comme les vases 11 et les assieltes cilés plus haul, a la fin du rigne d'Auguste ou sous relui de Tibere. Nous pensons qu'il ne dut son inspiralion qu'a des artistes formés aux écoles italiques, et a une tradition locale déja évoluée. Il est tout à fait vaisemblable qu'il apprit en mème temps les principes de l'arl décoratif el le lournage des fins rebords moulurés, d'un maîlre que nous ne connaissons pas encore, peut-être italien.

Nous avons vu que l'on peut relier a trois fragments de ces vases 29 "de l'école d'Alepomarus", le $n^{0} 1$ des vases 11 roannais par l'intermédiaire d'un pelit décor de remplissage cruciforme. Nous avons vu aussi que l'on peul attribuer à un mème potier, ou à un même atelier, plusieurs autres ralices parce qu'ils ont des oves ou des decors communs. On conclura - sans que l'on puisse déterminer une chronologie possible à l'intérieur de notre série arverne en raison de l'absence de renseiEnements de fouilles - - que l'on a fabriqué en même temps des vases 11 et des vases 29 trè précoces. On peut itre surpris que les fouilles de Roanne aient fourni huit vases 11 de Lezoux. el, selon le rapport de Déchelelle, aucun vase 29 arverne. Au Musée de Roanne, nous ne voyons que le fragment signalé en mème lemps que le calice $n^{0} 1$, qui puisse avoir une provenance locale. Nous pensons que les poliers lédosiens ont commencé par faire des ralères pour concurrencer les importations arétines qui arrivaient dans la région assez couramment. et a Roanne en particulier. Ils y sont assez bien parvenus. commercialement parlant, si l'on considère la proportion des vases donnés par les fouilles, dans leur élat actuel : sept ou huil arvernes contre deux arétins. A cetle époque, le vase 29 élait encore probablement peu répandu, et moins demandé sur le marché.

Ces vases 11 sont-ils les premieres imitations décorées de ces fabriques? On peut, pensonsnous, leur ajouter les copies de vases d'Aco trouvées en deux sites : les unes dans la nécropole Chassagne, à Lezoux, fabriquées vraisemblablement sur place ${ }^{58}$, comme le vase 11 recueilli dans le même cimetière; les autres dans l'oppidum de Gergovie, à 25 kilomètres environ à vol d'oiseau de Lezoux. "A còlé des véritables gobelets d'Aco, remarquables par leur pâte tendre el la technique parfaile du moulage el du décor en relief. M. Halt avait décelé la présence, sur le plateau, d'imitations que caractérisent une pàte très dure el lrès cuite, un décor exclusivement exéculé à la rouletle et le plus souvent strié, et surtout une couverte de peinture rouge apposée intérieurement et extérieurement ${ }^{59}$." M. I abrousse en a recueilli d'autres après lui. Ce dernier fouilleur a trouvé aussi dans une citerne du mème oppidum, avec deux fonds de vases estampillés CY. ITEI et ATEI (?). donc dans un contexte aurustéen. une tasse a anse dont l'aspect général est celui d'un modiolus. forme exceptionnelle qu'aux alentours de l'ère chrétienne, certains potiers d'Arezzo, comme $M$. Perennius Tigranus, emprunterent à des prototypes hellénistiques ou à des rases de métal. L'exemplaire de Gerovie est une imilation voulue d'une production ilalique de cel ordre. Mal recouverte d'un enduit rouge assez tenace. qui recouvre extérieurement et inlérieurement l'ensemble. la pate. de couleur jaune, assez tendre et un peu feuilletée, ne rappelle en rien celle des vases italiques ${ }^{60}$. Comme l'officine la plus importante el la plus proche connue est celle de Lezoux. et que les vases de Roanne qui en proviennent vraisemblablemenl nous montrent une imitalion précoce de la céramique italique, on peut supposer, en altendant le

(58) R. Laxter, Germania, 19, 1935, p. 318-321 : Ohlexroth, Rei Crelar. Rom. Faul. Acla II, 1959, p. $41-47$.

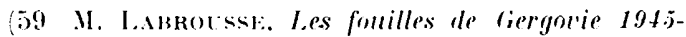
1946, dans Gallia, V1, 194., 1, p. 71.

(60) .I. I.ABrotsse, op. cil., p. s.3 et fier. 36, p. s5. 
produil de fouilles ultérieures sur l'emplacement des ateliers, que ces imitations augustéennes sont sorties des mains des artisans arvernes. Enfin, nous signalerons des vases noirs déposés au musée de Lezoux, qui pourraient bien ètre des imilations locales de céramique campanienne.

Si ces hypothèses étaient confirmées par des datations stratigraphiques, nous serions amenés a deux conclusions : $1^{0}$ les poliers arvernes, dont les activités élaient déjà importantes au ${ }^{\text {er }}$ siecle avant J.-C., se sont toujours eflorcés de ne point laisser envahir leurs marchés habituels par les produils italiques. Chaque fois qu'ils voyaient les produits étrangers gagner la faveur de leur clientile, its les ont imités rapidement, et non sans succès. Ils ont ainsi imité les produits italiques et spécialement les produits arétins lisses et moulés diss le début de notıe ère $; 2^{\circ}$ certains siles peuvent déjà servir pour esquisser l'élude de la chronologie précoce de Lezoux. L'oppidum de Gergovie a reçu des imitations italiques produiles par les officines voisines : gobelets d'Aco, modiolus, ete. Mais les vasts 11 de ces fabriques n'élaient pas répandus dans le commerce avant l'abandon de l'oppidum. Le cimetière de Roanne, qui a duré plus longtemps, nous montre que les vases caliciformes locaux ont fait leur apparition, mais non les vases 29 . Les vases carénés, comme les formes lisses, ont conquis, quelques années plus lard, un marché beaucoup plus vaste, puisqu'on trouve par exemple des estampilles d'Alepomarus dans plusieurs siles non seulement de la Gaule. mais de la Germanie et de la Cirande-Brelagne.

Létude des vases 11 de Roanne apporte done des éléments nouveaux sur les premières productions céramiques du Centre de la Gaule lille pose de façon plus précise les problèmes de la présence possible, en Auvergne, d'ouvriers italiques ou formés dans les fabriques italiques. de poinçons-matrices importés et de reliefs surmoulés, et la question des dates, encore imprécises. du débul de la fabrication de la lerre sigillée chez les Arvernes.

Ilugues Vk:RTET.

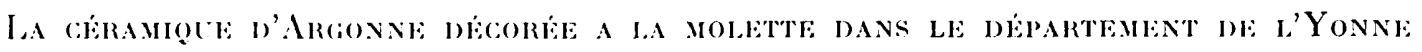

1)ans l'ouvrage fondamental de Chenet', le département de l'Yonne n'est pas représenté. Cependant l'auteur aurait pu, à l'époque où il réalisait ce répertoire, recenser dans les collections publiques de l'Yonne une demi-douzaine d'exemplaires. Ne pouvant sans doute faire le déplacement, il tenta une enquète, qui apparemment n'aboulit pas. La faiblesse du chiffre ne provient pas d'une médiocrité éventuelle des relations gallo-romaines entre l'Yonne el les ateliers d'Argonne, mais, comme on le verra, du manque d'informations des archéologues des générations précédentes. In fait on peut considérer que les potiers d'Argonne

(1) G. Cuw: La céramique gallo-romaine d'Argonne da $I^{\circ} \mathrm{e}$ siccle el la lerre sigillee décoree a la molelle, Màcon, 1941. ont toujours alimenté une clientèle en cette région. Au re siècle, la diffusion de leurs produits prend une grande extension avec la disparition des ateliers du Centre, et l'on pourrait aisément en constituer un échantillonnage (fig. 1).

Jusqu'à notre époque, la céramique décorée il la molette a eu contre elle une qualité fréquemment médiocre, et surtout de nous parvenir le plus souvent en tessons de petite dimension. l)'ou le dédain habiluel des ramasseurs. Cependant Augusla Hure, conservatrice du musée de Sens, n'avail pas négligé les quelques morceaux qu'elle avail pu rencontrer, sans toutefois s'y attarder. Seuls les cimetières procurent des vases complets, intacts mème. Mais, a ce jour, on ne possede pas dans le département une documentation notable sur les tombes du re siecle. A sens, une seule 